\title{
PLANOS DE ARQUITECTOS ESPAÑOLES PUBLICADOS EN ROMA (S. XIX): EL TEATRO DE MARCELO Y EL SANTUARIO DE HÉRCULES VENCEDOR
}

\author{
POR \\ JORGE GARCÍA SÁNCHEZ \\ Escuela Española de Historia y Arqueología en Roma (CSIC)
}

\section{RESUMEN}

En el siglo XVIII el estudio de los monumentos de la Antigüedad condujo a numerosos arquitectos a Roma, incluidos los españoles, en una época en la que predominaba en las artes europeas una contemplación del pasado grecorromano como solución estética y respuesta teórica al caduco arte barroco. Estos trabajos constituyen una importante documentación gráfica del estado de los monumentos clásicos en aquel entonces, y reflejan las inquietudes arqueológicas del Siglo de la Ilustración. Al tratarse de una ciencia ya perfectamente desarrollada, la arquitectura abordó el análisis de la Antigüedad con una precisión inexistente en la mentalidad anticuaria, como demuestran los dos ejemplos que ofrecemos: la elaboración de los planos del Teatro de Marcelo y del Santuario de Hércules Victor.

\section{SUMMARY}

In the eighteenth century, numerous architects, including Spaniards, travelled to Rome to study the ancient monuments, at a time when a view of the Greco-Roman past prevailed in European art as an aesthetic solution and theoretical answer to outdated Baroque art. These works constitute an important graphic document of the condition of the classic monuments at that time, and they reflect the archaeological interest of the Enlightenment. As a perfectly developed science, architecture approached the analysis of Antiquity with a precision that did not exist in antiquarian mentality, as demonstrated in the two examples we offer here: the elaboration of the archaeological plans of the Theatre of Marcellus and the Sanctuary of Hercules Victor.

PALABRAS CLAVE: Arqueología. Arquitectura. Teatro de Marcelo. Santuario de Hércules Victor. Pedro José Márquez. Silvestre Pérez. Evaristo del Castillo. Isidro González Velázquez.

KEY WORDS: Archaeology. Architecture. Theatre of Marcellus. Sanctuary of Hercules Victor. Pedro José Márquez. Silvestre Pérez. Evaristo del Castillo. Isidro González Velázquez.

\section{INTRODUCCIÓN}

Los monumentos antiguos de Roma sirvieron de modelo y fuente de inspiración de los arquitectos de toda Europa en los siglos XVIII y XIX ${ }^{1}$. La capital pontificia, punto de confluencia de las ideas estéticas y artísticas - basadas desde el Renacimiento en la comprensión y el estudio de la civilización romana en todos sus aspectos- que recorrían el continente europeo en el Siglo de las Luces, se convirtió en un taller privilegiado de formación de decenas de jóvenes en los distintos ramos de las Nobles Artes. Roma, denominada entonces el «Teatro del Mundo», desvelaba a través de una temprana e inmadura arqueología lo que su rico patrimonio podía ofrecer a eruditos y artistas, hecho que motivó que las nacientes academias subvencionaran viajes de estudios a sus discípulos a fin de que se instruyeran en el gusto que comenzaba a despuntar, de corte clasicista, el cual habitualmente se etiqueta y generaliza con el nombre de estilo neoclásico.

Aunque a un nivel cuantitativamente muy inferior al de sus colegas europeos, los arquitectos, pintores y escultores españoles efectuaron el viaje de Italia y se instruyeron en los talleres y en los ambientes académicos romanos, dejando una huella detectable de su paso por la ciudad del Tíber $^{2}$. La promotora de estos desplazamientos fue sobre todo la Real Academia de Bellas Artes de San Fernando, gracias a un sistema de pensiones distribuidas mediante oposición que se prolongaban durante cuatro años, y cuya contrapartida estribaba en la remisión anual a la institución de las obras que demostrasen los progresos de sus alumnos, en el caso de los arquitectos, de planos

\footnotetext{
1 A este respecto, François Nizet, Le voyage d'Italie et l'architecture européene (1675-1825), Bruselas-Roma 1988.

2 Véase Leticia Azcue Brea, «Los escultores españoles y las pensiones en Roma en la segunda mitad del siglo XVIII», Goya, 233, 1993, pp. 281-288; Jesús Urrea, «Pintores españoles en Roma a mediados del siglo XVIII», Boletín del Museo e Instituto "Camón Aznar», LXXV-LXXVI, 1999, pp. $367-$ 386; Pedro Moleón, Arquitectos españoles en la Roma del Grand Tour 1746-1796, Madrid 2003.
} 
de monumentos antiguos: debían consagrarse a su análisis pormenorizado, ya se mantuvieran enteros o arruinados, tenían que medirlos y dibujarlos, señalar la decoración que conservaban, y proyectar su reconstrucción ideal. Estas propuestas de restitución de las ruinas requerían de una escrupulosa documentación en las bibliotecas romanas acerca de las fuentes clásicas en las que se recogía la historia del monumento, la numismática ayudaba a reconstruir su aspecto parcial o completamente desaparecido, en conjunción con las operaciones arqueológicas. Todas estas labores se reflejaban en las memorias que acompañaban a los diseños de los pensionados explicando su proyecto, en ocasiones un compendio de las noticias que la tradición anticuaria transmitía del monumento en cuestión, o un diario de excavaciones si por entonces se procedía a desenterrarlo. Así, los envíos de los arquitectos muestran el método de acercamiento a los vestigios del pasado de mayor cientificismo en los siglos XVIII y principios del XIX, al sustentarse en una disciplina acreditada, con unas herramientas definidas y cuyo objetivo estribaba en el conocimiento de la arquitectura grecorromana, en lugar del mero deseo de sacar a la luz mármoles con los que decorar las galerías nobiliarias o que poner a la venta en el mercado anticuario.

No insistiremos en este trabajo sobre una cuestión acerca de la cual ya tuvimos oportunidad de extendernos en otra ocasión, concerniente al desaprovechamiento del rico material gráfico producido por los arquitectos españoles que viajaron a Italia, el cual, lejos de destinarse a ilustrar posibles publicaciones de arqueología o de arquitectura clásica, permanecieron circunscritos y malogrados en el estrecho marco de la enseñanza académica ${ }^{3}$. Motivaciones económicas e institucionales, así como la rígida percepción de los fines que debía perseguir la formación de un arquitecto en el extranjero, impidieron que estos artistas se situaran a la par que los ingleses y franceses en el descubrimiento y divulgación por toda Europa de los restos existentes de la Antigüedad, hecho que ya señalaron con pesar Fernando Chueca y Carlos de Miguel en el

\footnotetext{
${ }^{3}$ Jorge García Sánchez, «Las pensiones de la Academia de San Fernando en Italia: artistas españoles en el debate arqueológico y arquitectónico en torno a la Antigüedad de los siglos XVIII y XIX», en José Beltrán Fortes, Beatrice Cacciotti y Beatrice Palma (eds.), Arqueología, Coleccionismo y Antigüedad. España e Italia en el siglo XIX, Sevilla, Universidad de Sevilla 2006, pp. 193-216. En el marco del academicismo francés encontramos que si bien existió la voluntad a partir de 1815 de grabar y publicar regularmente los envíos anuales de sus pensionados, las publicaciones que se llevaron a cabo fueron resultado de la iniciativa privada de los arquitectos. Frank Salmon, Building on Ruins. The Rediscovery of Rome and English Architecture, Hampshire 2000, pp. 89 y 90.
}

caso de Juan de Villanueva ${ }^{4}$. Por ello presentamos aquí sendos proyectos dieciochescos pertenecientes a arquitectos de la Real Academia de San Fernando de Madrid, de ninguna repercusión en nuestro país, pero que sin embargo sí fueron publicados en Roma, y se insertaron en el debate que el anticuariado mantenía entonces acerca de los monumentos en que se centraban, el santuario de Hércules Victor de Tívoli y el Teatro de Marcelo; éste apareció en los Monumenti di fabbriche antiche estratti dai disegni dei piu celebri autori (1803) recopilados por Giovanni Battista Cipriani, mientras que aquél lo hizo en Illustrazioni della Villa di Mecenate in Tivoli (1812), obra del religioso Pedro José Márquez. Los autores de los dibujos fueron los arquitectos neoclásicos Isidro González Velázquez (1765-1840), Silvestre Pérez (1767-1825) y Evaristo del Castillo (1769-1798), presentes en Roma entre 1791 y 1796 gracias aquél a una pensión del rey Carlos IV y de la Academia madrileña los dos últimos ${ }^{5}$. Muchos otros de sus proyectos se han extraviado definitivamente ya que no fueron grabados para su publicación, si bien la Biblioteca Nacional conserva una colección de más de cuarenta dibujos relativos a la estancia italiana de Velázquez, en los que se aprecia la meticulosidad de los estudios que los pensionados ejecutaban de los monumentos del pasado (y en general de los restos materiales de la cultura romana) y cómo convergían en ellos la calidad pictórica de un artista y la precisión científica y vitruviana de un arquitecto $^{6}$. A pesar de que no pasaron por la imprenta, el arqueólogo Luigi Canina recordaba todavía avanzado el siglo XIX los planos realizados en el Foro por Velázquez y Castillo, seguramente los del templo de Antonino y Faustina, que ambos habían reflejado sobre el papel en $1793^{7}$ (Figs. 1 y 2). Los ejemplos de dibujos arquitectónicos de pensionados extranjeros im-

\footnotetext{
${ }^{4}$ Fernando Chueca y Carlos de Miguel, La vida y las obras del Arquitecto Juan de Villanueva, Madrid 1949, pp. 77 y 78.

${ }^{5}$ Consúltese sobre ellos Carlos Sambricio, Silvestre Pérez: arquitecto de la Ilustración, San Sebastián 1975; Íd., «Un álbum de dibujos poco conocido: el de Silvestre Pérez en la Biblioteca Nacional», Archivo Español de Arte, XLVI, 1973, pp. 45-57; Pedro Moleón, Arquitectos españoles..., op. cit. $n .2$, p. 279 y ss.

${ }^{6}$ Esta colección de dibujos ha sido reproducida parcialmente en Pedro Navascués Palacio, «Los discípulos de Villanueva. Isidro Velázquez», en AA.VV., Juan de Villanueva: arquitecto 1739-1811, Madrid 1982, pp. 71 y 161-163; Pedro Moleón, «Las luces y el antiguo», introducción a Paulantonio Paoli, Rovine della città di Pesto, Madrid 2002, pp. 27 y 28; Íd., Arquitectos españoles..., op. cit. n.2, pp. 354-373; Delfín Rodríguez Ruiz, «El orden dórico y la crisis del vitruvianismo a finales del siglo XVIII: la interpretación de Pedro José Márquez», Fragmentos, 8 y 9, 1986, pp. 46 y 47.

7 Luigi Canina, Esposizione Storica e Topografica del Foro Romano e sue adiacenze, Roma 1845 (2. ${ }^{\text {ed.), p. } 9 .}$
} 


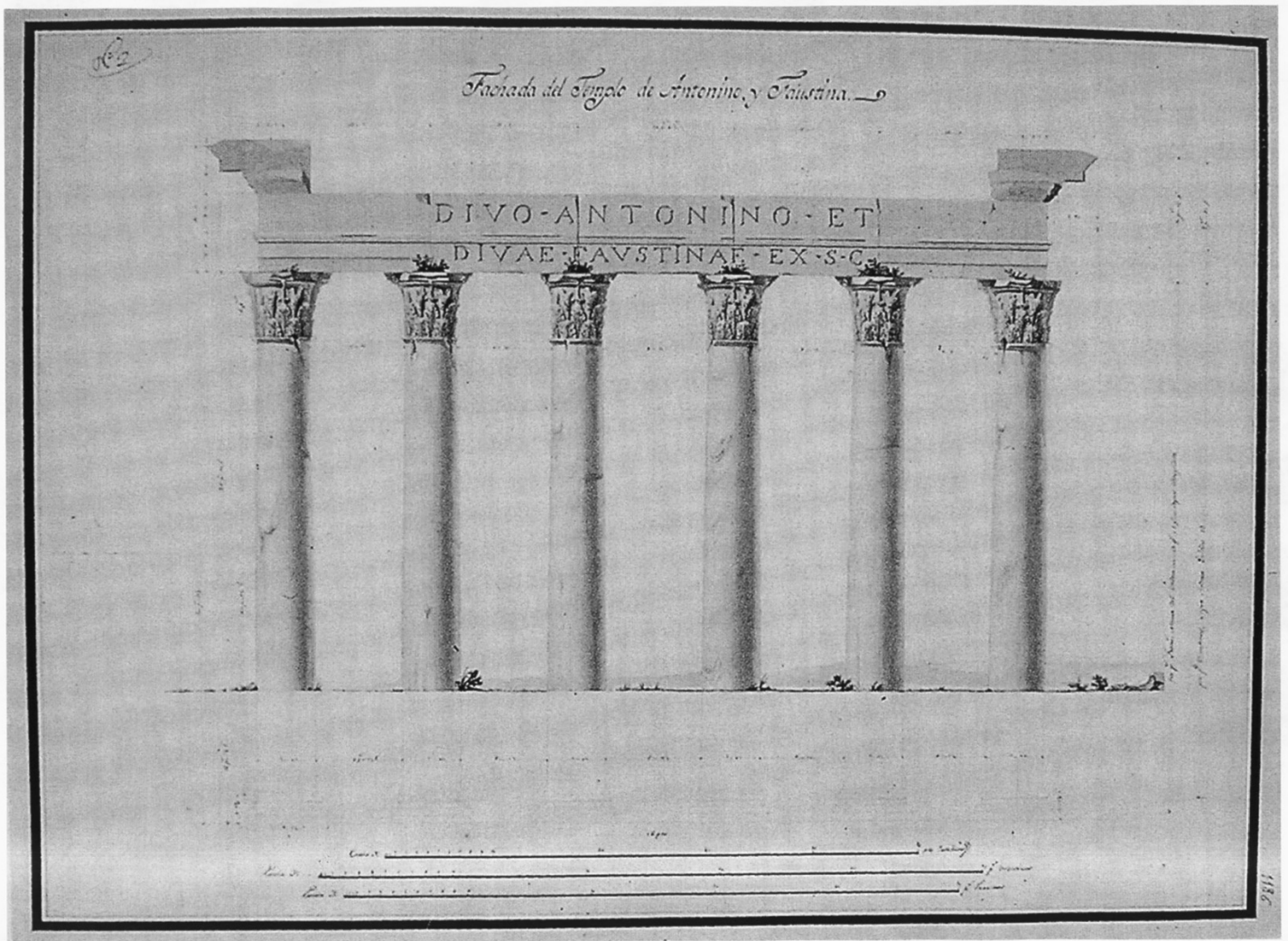

Fig. 1. Isidro González Velázquez, Fachada del Templo de Antonino y Faustina, 1793, BNM. BA-1186.

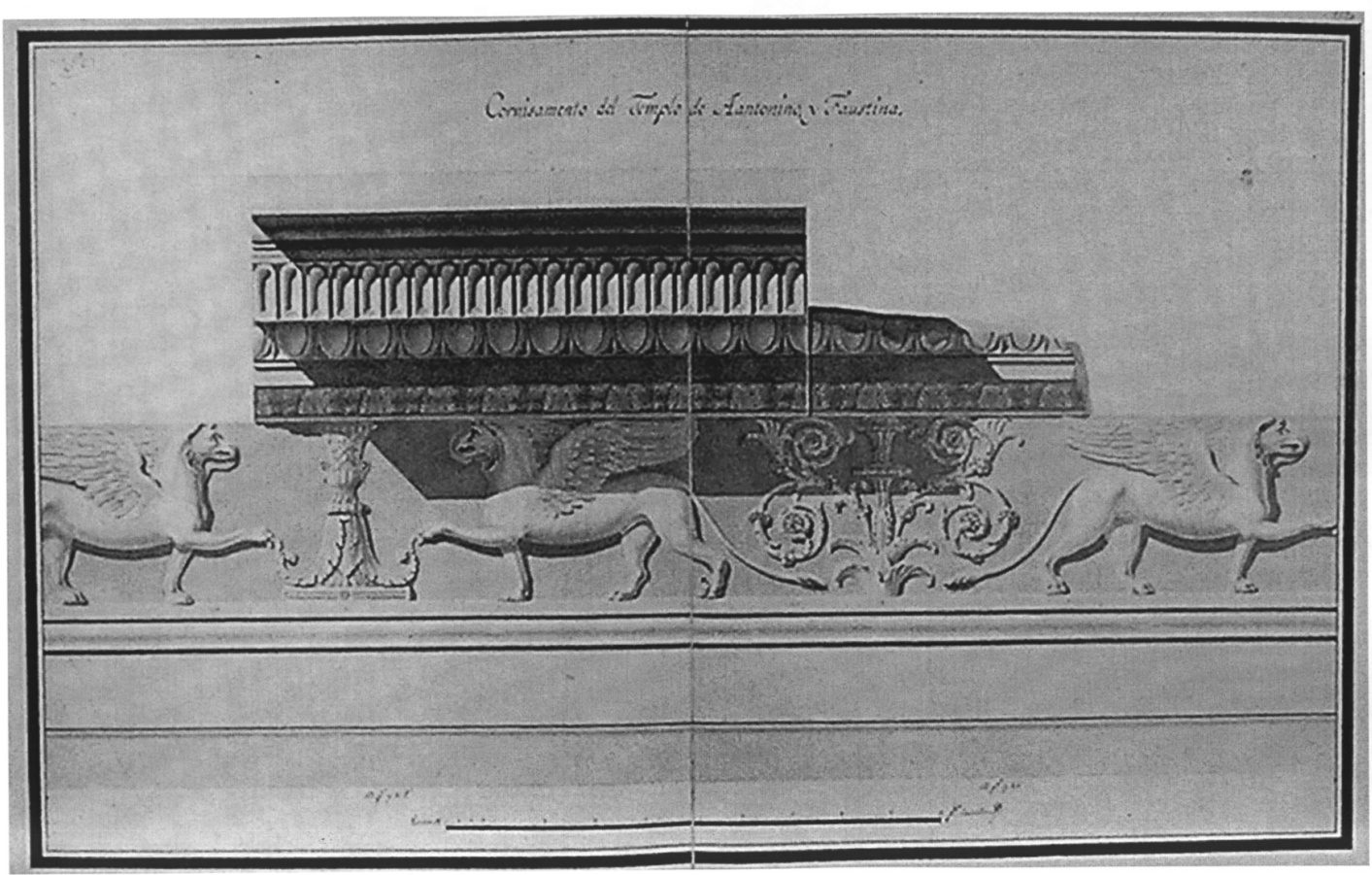

Fig. 2. Isidro González Velázquez, Cornisamento del Templo de Antonino y Faustina, 1793, BNM. BA-1190. 
presos en Italia se multiplican si dirigimos la mirada hacia los artistas franceses, muchos de los cuales profesaban incluso la técnica del grabado y difundieron algunas de sus propias obras durante su estancia en la Urbe. Así, no resulta excepcional que Legeay, Duflos y Bellicard colaboraran con Piranesi en la elaboración de las estampas romanas del abate Venuti, o que Lorrain diseñara la viñeta del título de Opere varie (1750) del veneciano, cuyo taller se ubicaba además en la vía del Corso, frente a la Academia de Francia ${ }^{8}$.

Introduzcamos brevemente a las figuras implicadas en las dos publicaciones y las relaciones que los unían. El personaje al que estos pensionados debieron su introducción en los círculos del anticuariado romano y en sus relaciones con los teóricos de las artes y la arqueología del momento que sacaron a la luz sus dibujos fue el diplomático aragonés José Nicolás de Azara (1730-1804), ministro plenipotenciario ante la Santa Sede tanto de Carlos III como de su sucesor en el trono entre 1794 y $1798^{\circ}$. A falta de un director de los pensionados que orientara los estudios de los arquitectos en la Ciudad Eterna, Azara los tomó bajo su tutela, la cual, como observaremos, fue decisiva en los trabajos que llevaron a cabo en esos años y que devinieron objeto de envío a la Academia. También el mexicano Pedro José Márquez siempre reconoció en él al promotor de sus iniciativas, en su caso de índole literaria. Márquez era uno de tantos jesuitas a quien el ministro en Roma brindó su amistad y protección, muy numerosos en Italia desde su expulsión en 1767, como también es el caso de Esteban de Arteaga, su bibliotecario y colaborador en las ediciones de los autores clásicos. La decisión de Azara se halla detrás de varias de las obras del anticuario mexicano, quien podía escribir tanto sobre estética, al igual que Arteaga, como de arqueología clásica y precolombina, siendo sin embargo un autor de mucho menor difusión en España que en Italia ${ }^{10}$. La relación de estos arquitectos con Pedro Márquez, miembro de la Academia Romana de Arqueología, se remonta ya a sus años iniciales de pensión, puesto que en 1792 Isidro González Veláz-

${ }^{8}$ Janine Barrier, Les architectes européens à Rome 17401765. La naissance du goût à la grecque, París 2005, p. 46.

${ }^{9}$ Citaremos la obra más completa hasta el momento acerca de su faceta de arqueólogo ilustrado, Beatrice Cacciotti, «La collezione di José Nicolás de Azara: studi preliminari», Bollettino d'Arte, 78, 1993, pp. 1-54.

${ }^{10}$ Sobre Márquez, Delfín Rodríguez Ruiz, «El orden dórico...», op. cit. n.6; Juana Gutiérrez Haces, «Los antiguos mexicanos, Vitruvio y el padre Márquez», en AA.VV., Historia, leyenda y mitos de México: su expresión en el arte, México 1988, pp. 177-97; Justino Fernández, «Pedro José Márquez en el recuerdo y en la crítica», Anales del Instituto de Investigaciones Estéticas, VIII, 32, 1963, pp. 5-19. quez había acompañado al ex-jesuita mexicano y al erudito francés Petit-Radel en sus excursiones arqueológicas por los alrededores de Roma, y hacia 1795 Silvestre Pérez había examinado las ruinas de la Villa de Plinio en la Laurentina junto a aquéllos, cuyo resultado sería la publicación un año después de Delle Ville di Plinio il Giovane por parte de Márquez ${ }^{11}$. En 1803 la planta del llamado templo de Serapis de Pozzuoli - en realidad el macellum del barrio portuario de la antigua Puteoli-, delineada por Velázquez, sería introducida por Márquez en un apéndice de su obra Dell'Ordine Dorico... ${ }^{12}$, en el que disertaba acerca de las reconstrucciones sucesivas practicadas en el monumento, la última de las cuales databa en el reinado de Marco Aurelio.

Por su lado, Giovanni Battista Cipriani era uno de los grabadores más reputados de Roma en el cambio de siglo, autor de diferentes recopilaciones sistemáticas de las construcciones antiguas y modernas de la ciudad. Amén de coincidir con Azara en el cenáculo privado del arquitecto y filósofo Leonardo De Vegni, quien congregaba entre otros a reconocidos cultores de la Antigüedad como Francesco Milizia, Onofrio Boni, Carlo Fea y Ennio Quirino Visconti ${ }^{13}$. Cipriani había ya grabado algunas de las imágenes contenidas en los escritos de Márquez, como las alusivas a las edificaciones dedicadas a espectáculos públicos en época romana ${ }^{14}$, o al tiburtino santuario de Hércules, considerado en la época la Villa de Mecenas, como veremos a continuación.

${ }^{11}$ P. J. Márquez, Delle Ville di Plinio il Giovane, opera di D. Pietro Marquez Messicano con un appendice Su gli Atri della S. Scrittura, e gli Scamilli impari de Vitruvio, Roma 1796. Carlos Sambricio - y a partir de él también Pierre Pinon-supone de Silvestre Pérez la planta de la Villa de Plinio publicada por Márquez en su volumen, plano que efectuó sin embargo el propio mexicano. Carlos Sambricio, «La tercera generación ilustrada: la arquitectura de la Revolución», en La arquitectura española de la Ilustración, Madrid 1986, pp. 268 y 269; P. Pinon, «La Villa Laurentine de Pline le Jeune», en AA. VV., La Laurentine et l'invention de la Villa Romaine, París 1982, p. 66.

12 Íd., Dell'Ordine Dorico. Ricerche dedicate alla Reale Academia di S. Luigi di Saragoza da D. Pietro Marquez. Mexicano con Apéndice sopra un'antica tavola di Pozzuolo, Roma 1803, lám. 9, fig. 1. También, Jorge García Sánchez, «El viaje al sur de Italia del arquitecto Isidro González Velázquez», Academia, 94 y 95, 2002, pp. 27-44.

${ }^{13}$ Elisa Debenedetti, «Un'idea di Roma 1750-1823. La linea teorica dell'architettura», en Architetti e ingenieri a confronto. L'immagine di Roma fra Clemene XIII e Pio VII, I, Studi sul Settecento romano, 22, 2006, pp 12 y 13. Sobre Cipriani, Dizionario Biografico degli Italiani, Roma 1981, vol. 25, pp. 747-749.

${ }^{14}$ P. J. Márquez, Esercitazioni architettoniche sopra gli spettacoli degli antichi con appendice sul bello in generale, Roma 1808. Cirpiani no sólo era el autor de los grabados de esta obra sino también el de algunos de los dibujos en que se basaban. 


\section{LOS PLANOS DE LA VILLA DE MECENAS (SANTUARIO DE HÉRCULES VICTOR) DE SILVESTRE PÉREZ Y EVARISTO DEL CASTILLO}

\section{II.1. Historia DE UNA PUBLICACIÓN}

En 1794, después de los envíos previos relativos a los templos de Cástor y Pólux, y de Antonino y Faustina, en el Foro Republicano, el embajador José Nicolás de Azara enfocó las investigaciones de Pérez y Castillo hacia uno de los restos arquitectónicos de los más espléndidos, a la par que expoliados, de la ciudad de Tívoli. En un escrito remitido por los dos arquitectos al secretario de la Real Academia de San Fernando, Isidoro Bosarte, le ponían al corriente del trabajo en que se habían embarcado de la mano del diplomático aragonés: «Habiendose, pues, descubierto en Tivoli parte de uno de los patios de la Vila (sic) de Mecenas de correctisima arquitectura y unico exemplar del orden dorico griego q.e. existe en Italia; noticioso el Ministro de S.M. en esta Corte de tan feliz descubrimiento para las bellas artes, nos insinuó y aun ordenó que sería útil pasar à medirlo y levantar planos geometricos exactos de todos los fragmentos q.e se ven y subterraneos de la referida Vila. S.E. mismo nos conduxo al parage y mediante su instrucción hemos dibujado lo q.e. existe, para despues suplir lo que falta» ${ }^{15}$.

Las publicaciones que han analizado la historiografía del templo de Hércules Victor (Fig. 3) y los escritos que abordan la figura de José Nicolás de Azara coinciden en señalar al embajador como autor de unas presuntas excavaciones arqueológicas desarrolladas hacia 1794 en los terrenos de la antigua construcción republicana, de las cuales no se suele especificar su lugar concreto, o los resultados obtenidos $^{16}$. El arqueólogo italiano C. F. Giuliani sí iba más allá apuntando que el embajador «fece sgombrare dalle vigne il tratto compreso grosso modo tra il tempio ed il porticato che dà sull'Aniene» ${ }^{17}$, es decir, el área que constituía la mitad septentrional del santuario, mientras que Beatrice Cacciotti y Urríes de la Colina encontraban en las motivaciones de Azara para excavar en este punto el deseo de aumen-

\footnotetext{
${ }^{15}$ Archivo de la Real Academia de San Fernando (en adelante, ASF). leg. 49-6/1. Carta de Silvestre Pérez y Evaristo del Castillo a Isidoro Bosarte de 25 de junio de 1794.

${ }^{16}$ Por citar algunos ejemplos, B. Cacciotti, «La collezione...», op. cit. n. 9, pp. 17 y 18; Maria Grazia Fiore y Stefano Gizzi, Tivoli. Il santuario di Ercole Vincitore, Milán 1998 , p. 16.

${ }_{17}$ C. F. Giuliani, Tibur. Forma Italiae. Regio I, Roma 1966-1970, vol. VII, p. 168.
}

tar su colección de antigüedades ${ }^{18}$. El verdadero interés del caballero Azara estribaba en que no cayera en el olvido la arquitectura dórica del santuario, manteniendo viva su memoria a través de una obra escrita — de la que habría de encargarse Pedro José Márquez-, y de los dibujos de los pensionados, en definitiva, la auténtica aportación del embajador para el conocimiento del monumento erigido junto al río Aniene, y que no carece ciertamente de una dimensión arqueológica. Relata el ex-jesuita mexicano que habiendo elegido el ministro español Tívoli como localidad de reposo, se paseaba habitualmente por entre los vestigios de las villas antiguas que se repartían por su campiña, admirando especialmente la de Mecenas. Consciente de la importancia de estas ruinas se puso de acuerdo con el Gobierno pontificio para que se descombrase la zona que «dalle vigne attuali si stende sino alle colonne del portico interno», es decir, la parte noreste del área sacra del edificio. Desenterrado este sector, que hoy sabemos que corresponde a un ángulo del primer pórtico del recinto que asomaba a la gran plaza donde se levantaba el templo, Azara hizo copiar el conjunto, creyendo que las obras de una moderna fundición pontificia que se estaba levantando allí derruirían las arcadas descubiertas ${ }^{19}$ (Fig. 4). La narración del padre Márquez es la versión más exacta acerca de la intervención de Azara en el santuario en estos momentos, salvo en uno de sus detalles. Las operaciones de reforma para adaptar los pertrechos industriales de la armería de Pío VI (inaugurada en 1795) en los restos del complejo antiguo habían sido las causantes del hallazgo de ese pórtico ornado de medias columnas dóricas, y no el deseo de Azara de que se rescatara la arquitectura original del monumento. El propio diplomático nos lo confirma de su puño y letra en ocasión del envío de los planos de la villa a la Academia en 1795, cuando le comentaba a Bosarte lo siguiente: «Estas ruinas no han sido hasta ahora examinadas ni medidas Arquitectonicamente por nadie, no obstante que millares de turistas las dibujan todos los dias para componer vistas y paisajes, esto me movio a encargar a estos dos jovenes que levantasen un plano lo mas geometrico que se pudiese, aprobechando la ocasion de que de orden de este gobierno se excavaba y restauraba una parte de dhas.

${ }^{18}$ Beatrice Cacciotti, «Scavi Azara», en Beatrice Palma, (ed.), Le erme tiburtine e gli scavi del settecento. Uomini Illustri dell'antichità, I, 2, Roma 1992, p. 179; Javier Jordán de Urríes de la Colina, «El diplomático José Nicolás de Azara, protector de las bellas artes y las letras», Boletín del Museo e Instituto "Camón Aznar», LXXXI, 2000, p. 70.

19 P. J. Márquez, Illustrazioni della Villa di Mecenate in Tivoli, Roma 1812, pp. 3 y 4. 


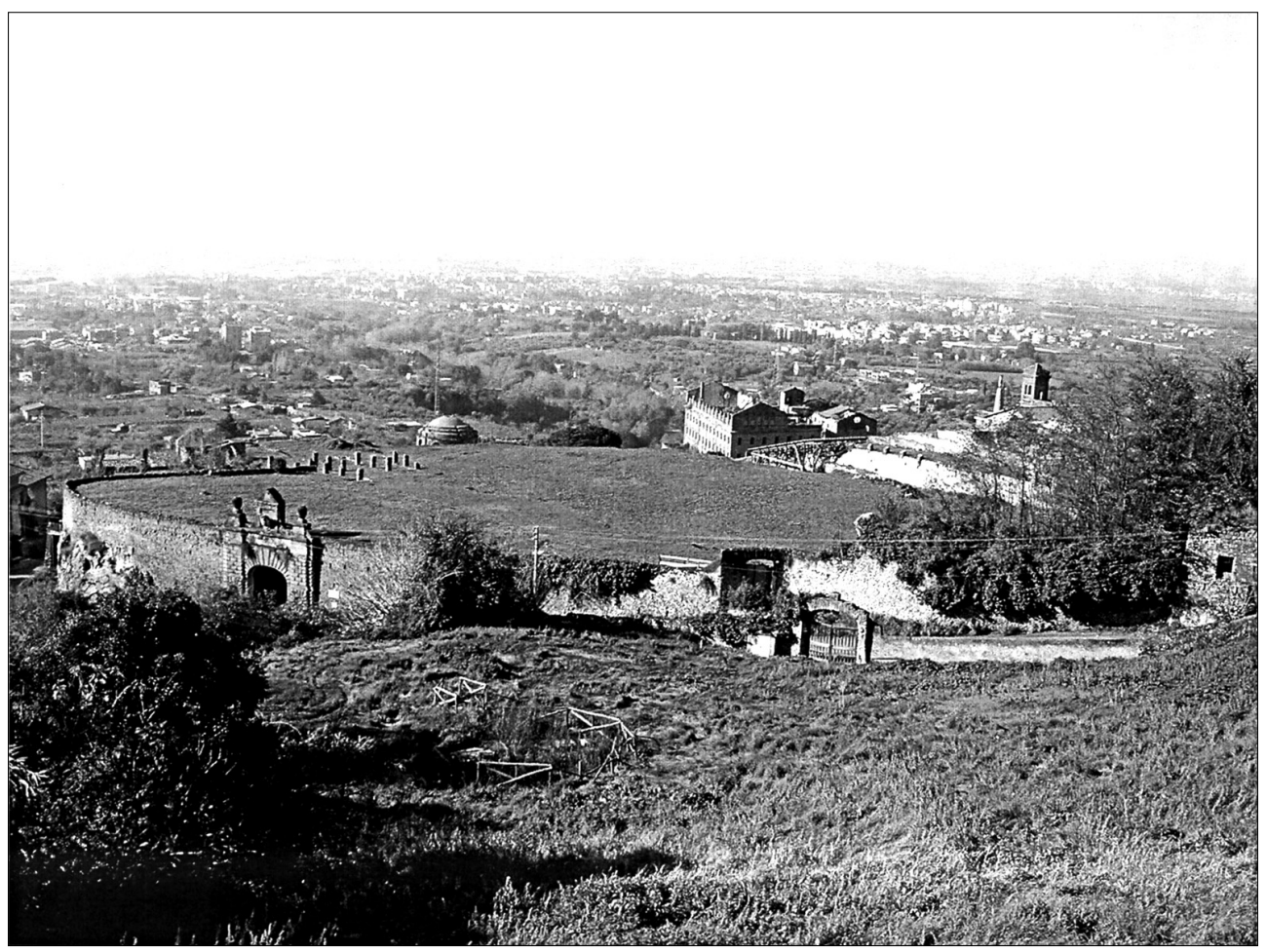

Fig. 3. Vista del santuario de Hércules Victor. Foto del autor.

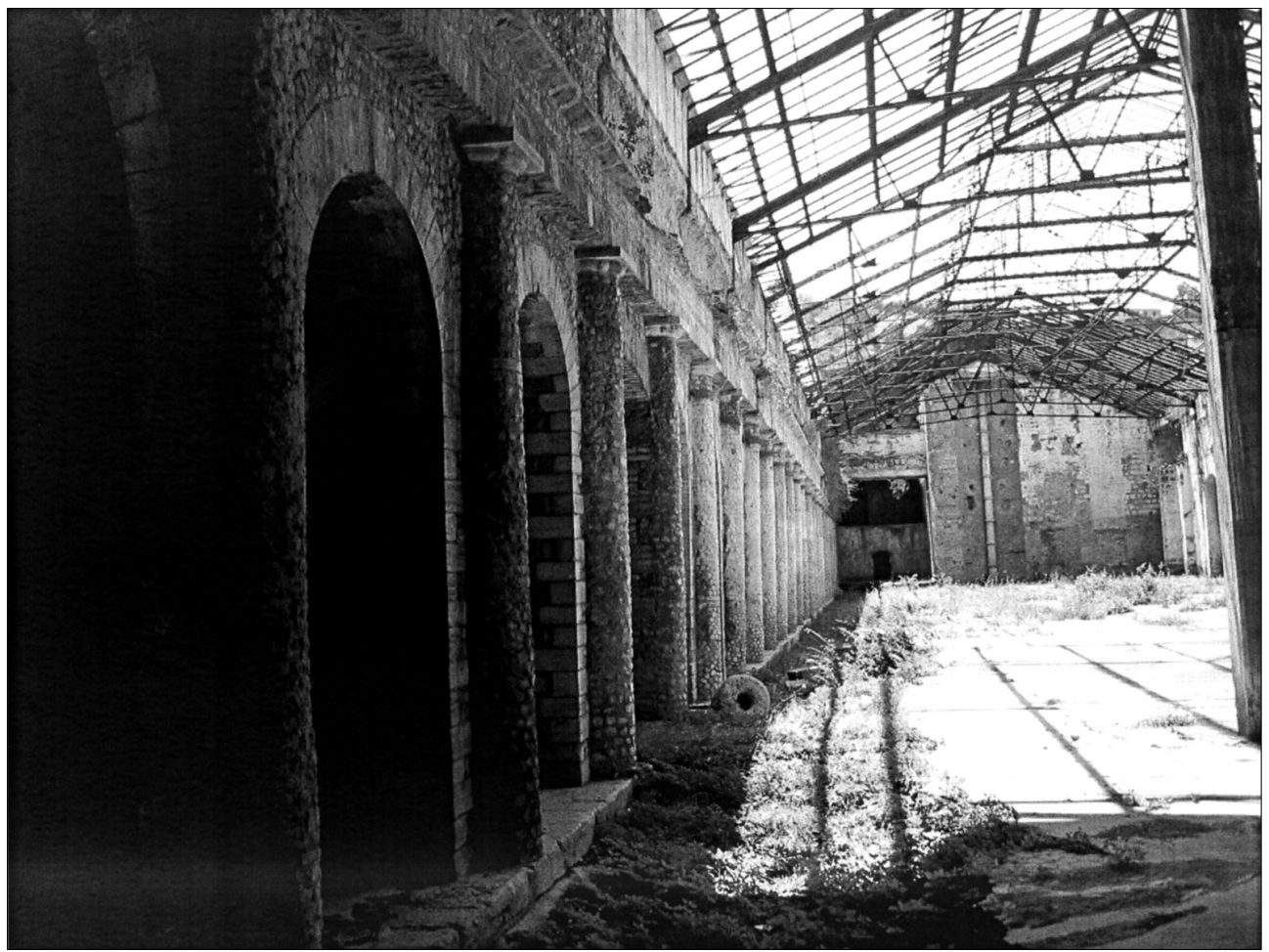

Fig. 4. Estado actual del pórtico del santuario. Foto del autor. 
ruinas para establecer una fabrica de Armas, aprovechando la gran cantidad de agua que pasa por ellas» ${ }^{20}$.

La inclusión del padre Márquez en el proyecto de José Nicolás de Azara no acaeció hasta que Pérez y Castillo concluyeron sus planos. En 1795 había aparecido la obra del ex-jesuita Delle case di città dei signori romani ${ }^{21}$, y se encontraba preparando la relativa a las residencias de campo de la Laurentina y la Toscana de Plinio. Azara consideró que el ex-jesuita era la persona más adecuada para componer el tipo de escrito que acariciaba, en vista de los análisis sobre la arquitectura clásica que había llevado acabo precedentemente.

Con los planos arquitectónicos en la mano Márquez acudió repetidas veces a Tívoli para contrastarlos con los restos del santuario y redactó su descripción, la cual presentó a Azara. Éste le manifestó su deseo de publicarla, si bien tenía en mente que se ampliase con una disertación relativa a la arquitectura griega en Italia, cuya edición correría a cargo del tipógrafo Giambattista Bodoni ${ }^{22}$. Esta obra incluiría una parte gráfica nutrida por los diseños de los arquitectos pensionados de diversos monumentos del pasado, como de los templos de Paestum, de Isidro González Velázquez, o del Teatro de Marcelo, de Silvestre Pérez (en colaboración con sus compañeros), además de los consabidos de la Villa de Mecenas $^{23}$. La partida del aragonés de la capital pontificia en 1798 y su propio fallecimiento unos años más tarde provocaron que no se cumpliera la idea de reunir en un volumen todos esos monumentos que empleaban el orden dórico. En las donaciones recibidas por la Real Academia de San Fernando entre 1796 y 1799 consta la entrega de un ejemplar de Delle case di città dei signori romani y una copia del escrito de la Villa de Mecenas ${ }^{24}$, que el padre Márquez expediría a Madrid poco después de terminar la redacción de su manuscrito. Mientras que una copia de los diseños de los dos arquitectos fue remitida a la Academia, Azara mantuvo los originales en su po-

${ }^{20}$ Archivo del Ministerio de Asuntos Exteriores. Santa Sede (en adelante, AMAE. ss). leg. 362. Carta de José Nicolás de Azara a Isidoro Bosarte de 10 de junio de 1795.

${ }^{21}$ P. J. Márquez, Delle case di città degli antichi Romani, secondo la dottrina de Vitruvio, Roma 1795.

${ }^{22} \mathrm{La}$ ingente correspondencia entre Azara y Bodoni, con quien emprendió numerosos proyectos editoriales, puede consultarse en Angelo Ciavarella, De Azara-Bodoni, Parma 1979, 2 vols.

${ }^{23}$ AMAE. ss. leg. 362. Carta citada de José Nicolás de Azara a Isidoro Bosarte de 10 de junio de 1795 .

${ }^{24}$ Distribucion de los premios concedidos por el Rey Nuestro Señor á los alumnos de las tres bellas artes hecho por la Real Academia de Bellas Artes de San Fernando en la junta pública de 13 de julio de 1799, Madrid 1799, p. 11. der y, todavía hacia 1800, encontrándose fuera de Italia, le decía a Bodoni que a su regreso pretendía que se los publicase, permaneciendo aquéllos entre las cosas que había dejado el ministro en Roma ${ }^{25}$. Tres años más tarde Márquez solicitaba de su amigo y benefactor, entonces embajador en París, los manuscritos originales de varios de sus escritos que Azara mantenía tras haberlos corregido, entre ellos el de Mecenas, el cual contenía una planta de la edificación que el ex-jesuita necesitaba para sus investigaciones a falta de los dibujos originales, traspapelados entre los cajones depositados en el palacio de España de Roma que contenían los cuadros, libros y porcelanas del diplomático aragonés ${ }^{26}$. Esto lo repetía asimismo el abate Uggeri, que en 1806 se lamentaba por la improbabilidad de que salieran a la luz todos los estudios y noticias recogidos acerca del santuario por Pérez y Castillo, a los que definía como «due valorosi architetti Spagnuoli», al conservarse todo el material entre las pertenencias del difunto Azara $^{27}$. Ni los planos de los pensionados ni el texto del padre Márquez permanecieron en el olvido, dado que con el auxilio de la Accademia Romana di Archeologia, y en tributo a la amistad que lo uniera con Azara, el ex-jesuita publicó finalmente en 1812 el libro Illustrazioni della Villa di Mecenate in Tivoli, con los grabados de G. B. Cipriani y V. Feoli. La obra no contenía todo lo que hubiese deseado Azara, ni tampoco todo el trabajo efectuado por Pedro José Márquez, ya que en 1814, J. T. Medina advertía en sus Noticias bio-bibliográficas de los jesuitas expulsos de América en 1767 de la exclusión en el escrito de aquél de un ensayo introductor relativo a la vida de Mecenas que el mexicano había redactado, y que hubiese querido ver publicado junto al material editado por la Academia Romana. Juana Gutiérrez Haces localizó esta disertación, titulada Commentari sopra la vita di Mecenate, en el manuscrito 113 (2242) del Fondo Jesuítico de la Biblioteca Nazionale Vittorio Emmanuele de Roma $^{28}$. La preocupación del padre Márquez por la arquitectura romana y su representación teórica en el texto vitruviano, además de en otras obras señaladas con ante-

\footnotetext{
${ }^{25}$ Bodoni comunicaba asimismo al embajador español en octubre de 1799 su deseo de que regresara a Italia, y así poder acompañarle a visitar las villas de Mecenas y Horacio. A. Ciavarella, De Azara-Bodoni..., op. cit. n. 22, vol. II, p. 148. 26 Biblioteca Nacional de Madrid (en adelante, BNM). Mss. 20084/12. Carta de P. J. Márquez a José Nicolás de Azara de 18 de julio de 1803.

27 Angelo Uggeri, Journées pittoresques des edifices de Rome ancienne, Roma 1800-1828, vol. VI, p. 71, n. 1.

${ }_{28}$ Juana Gutiérrez Haces, «Los antiguos mexicanos...», op. cit. n. 10, p. 191, n. 28.
} 
rioridad, fue objeto de su análisis en cuatro volúmenes inéditos redactados como una enciclopedia de arquitectura y conservados en la Biblioteca Nacional de Madrid, en el último de los cuáles su autor habría incluido tres de los diseños de los pensionados de la Villa de Mecenas si se hubiese llegado a publicar ${ }^{29}$.

\section{2. El SANTUARIO REPUBLICANO}

El ex-jesuita planteó su escrito como una descripción de los siete planos resultantes de la actividad desplegada durante casi dos años por los pensionados en los vestigios que todavía se mantenían en pie, siempre entendidos como residuos de una villa augustea en lugar de pertenecientes a un santuario republicano. Para comprender los trabajos de los pensionados y de Márquez tenemos por tanto que acudir a la realidad arqueológica del recinto consagrado a Hércules, y de las transformaciones acaecidas en él a lo largo de su historia.

El culto de Hércules Victor tenía su sede en Tívoli en un complejo que forma parte del conjunto de grandes santuarios laciales construidos a finales de la República (entre los siglos II y I a.C.), entre los cuales podemos mencionar los de Palestrina, Gabii, Nemi, Lanuvium o Terracina ${ }^{30}$. De la amplia área sacra que formaba parte de la fisonomía del monumento apenas se han conservado vestigios, siendo los de las galerías abovedadas del cuerpo del basamento que sustentaba el santuario los que en mejor estado han llegado hasta nuestros días ${ }^{31}$ (Fig. 5). Dos cuerpos porticados — como señalamos, el primero se encontraba decorado con la incorporación de semicolumnas dóricas entre las arcadas - cercaban la explanada frente al templo por tres de los cuatro lados del santuario, permaneciendo el cuarto abierto hacia la llanura. La plazoleta del área sacra, sepultada por una parte entre las fábricas modernas, y por otra bajo el prado formado actualmente, estaba compuesta por el templo dedicado a Hércules Vencedor, un teatro donde se efectuaban las representaciones vinculadas

${ }^{29}$ BNM. Mss. 2456-2459. Apuntamientos por orden alfabético pertenecientes a la arquitectura donde se exponen varias doctrinas de M. Vitruvio Polion. Obra compilada por D. Pedro Joseph Marquez, socio honorario de las Academias de Bellas Artes de Roma, de Madrid, de Florencia, de Bolonia, y de la Arqueológica Romana. Esta enciclopedia fue redactada entre 1784 y 1806, aunque en 1810 Márquez aún introducía algunos suplementos a su obra.

${ }^{30}$ F. Coarelli, I Santuari del Lazio in età repubblicana, Roma 1987.

${ }^{31}$ Acerca de las estructuras que constituyen la cimentación del santuario, Paola Olivanti, Antiche strade. Lazio. Via Tiburtina, Roma 1997, pp. 51 y 52.

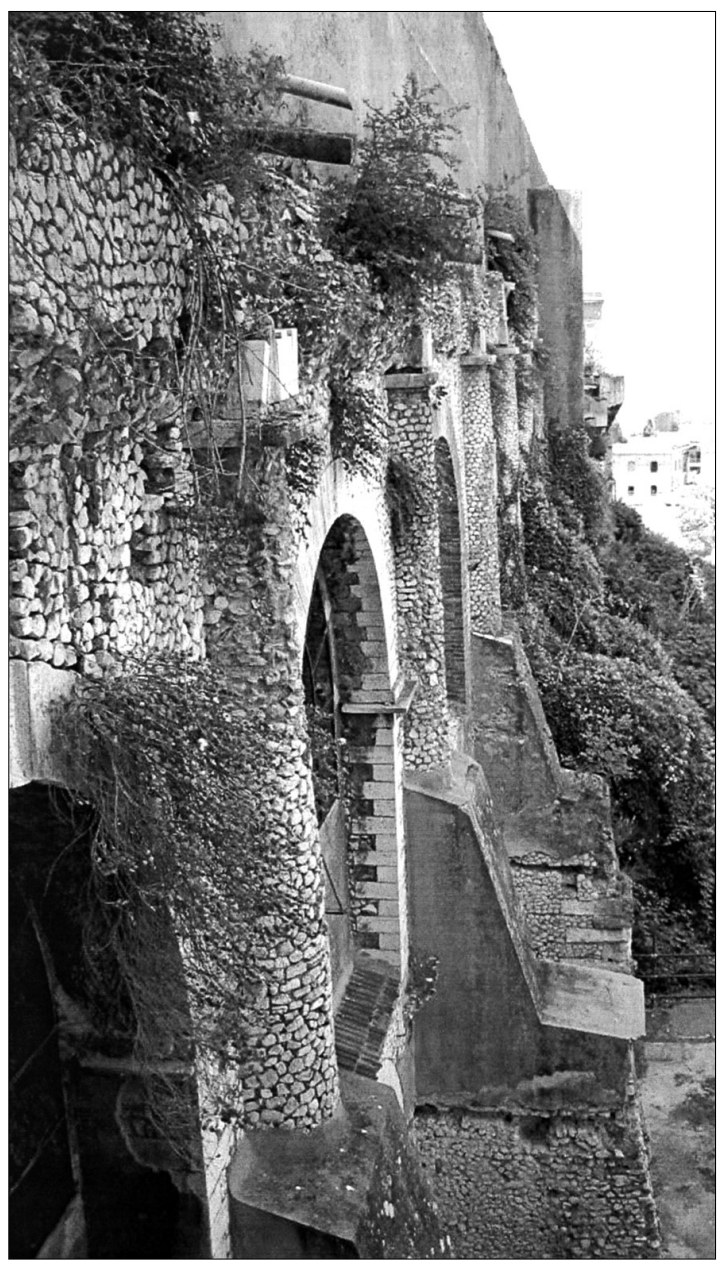

Fig. 5. Cuerpo del basamento del santuario. Foto del autor.

con los mitos de Hércules. Del recinto octóstilo de culto únicamente son visibles los restos del alto podio sobre el que se alzaba ${ }^{32}$ (Fig. 6).

En la parte norte de la fachada del monumento se localizaba la entrada de una via tecta — rebautizada como Porta Scura en el Medievo- que cubría el tramo de la Vía Tiburtina que lo atravesaba durante 150 metros, de los que actualmente solamente se mantienen 80 abovedados, a causa del derrumbamiento en el siglo Xvi de uno de los extremos del pasaje. A lo largo de la via tecta se dispusieron en los laterales una serie de ambientes, algunos identificados con tabernae y pequeños negocios que se suceden paralelamente, y otros con estructuras abovedadas vinculadas a la sustentación del conjunto del santuario ${ }^{33}$.

\footnotetext{
${ }^{32}$ F. Coarelli, I Santuari..., op. cit. n. 30, p. 90.

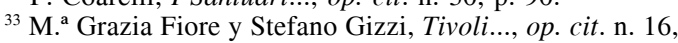
p. 32 .
} 


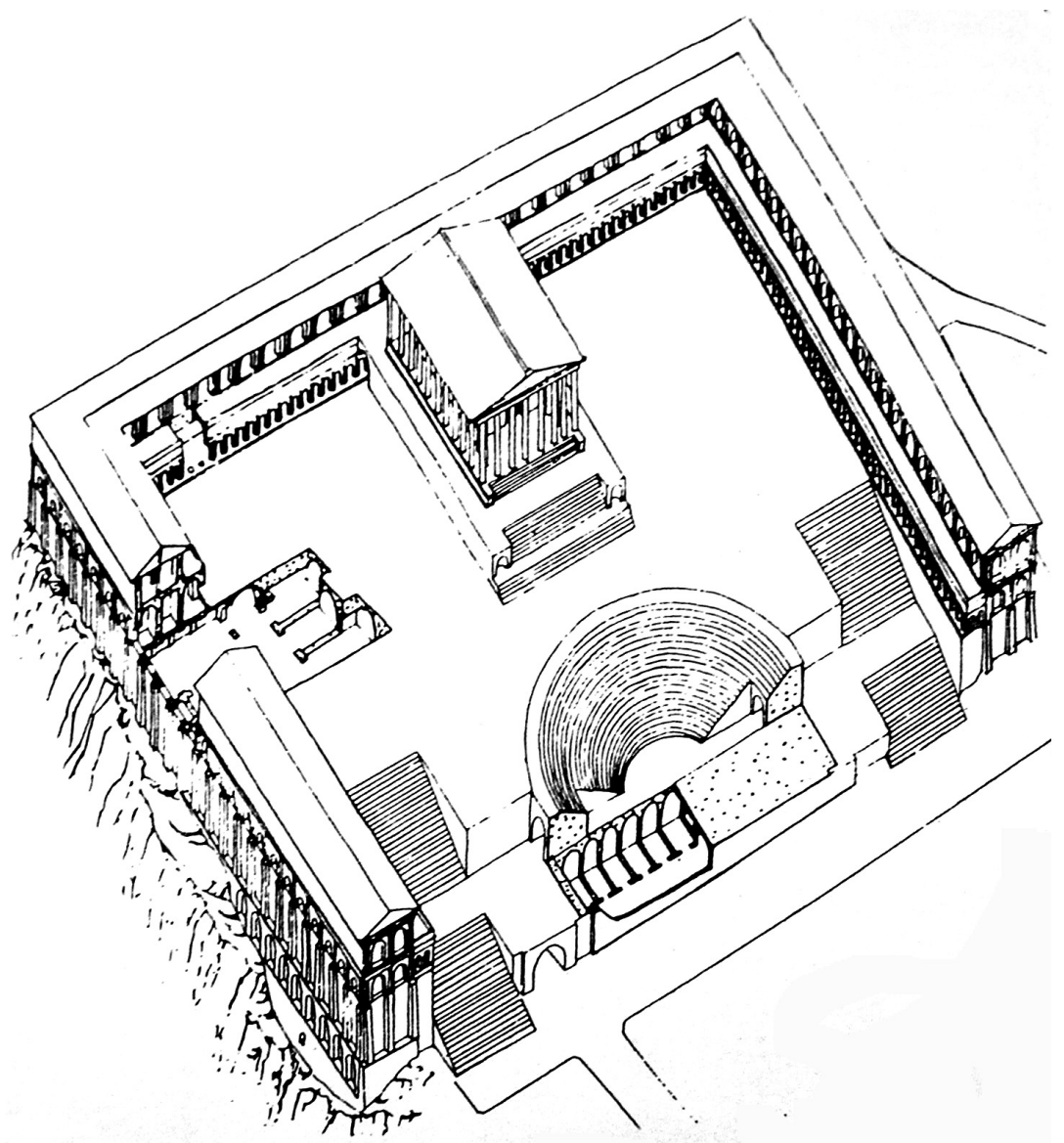

Fig. 6. Reconstrucción del santuario de Hércules Vencedor (C. F. Giuliani, 1970).

Cuando Silvestre Pérez y Evaristo del Castillo delinearon en 1794 la Villa de Mecenas se desarrollaban en ella las obras de acondicionamiento que consentirían la instalación de la fundición vaticana en el monumento. Ésta era una más de las explotaciones industriales a las que se había sometido el santuario de Tívoli desde el siglo xvII, y una de las causas de sus amplísimas transformaciones y de la introducción de estructuras modernas, aunque posiblemente también de su conservación ${ }^{34}$. Ya desde el siglo XII se documenta la instalación sirviéndose de

${ }^{34}$ Sobre las empresas industriales acometidas en el santuario de Hércules, C. F. Giuliani, Tibur..., op. cit., pp. 164 y 165; Ma . Grazia Fiore y Stefano Gizzi, Tivoli..., op. cit. n. 16, pp. 30 y 31; AA. VV., Italia Antiqua. Envois de Rome des architectes français en Italie et dans le monde méditerranéen aux XIX et XX siècle, París 2002, p. 61 y ss; Jorge García Sánchez, «Un esempio delle procedure di conservazione del patrimonio tiburtino alla metà dell' ottocento. Il santuario di Ercole Vincitore», Rivista Storica del Lazio, 19, 2003, pp. 57-68. los restos del monumento de dos iglesias con sus respectivos complejos monacales y sus terrenos cultivables, Santa Maria del Passo y San Giovanni in Votano, que se abandonaron a comienzos del siglo XVIII. De principios del siglo XVII en adelante se registra sin embargo la disposición de diversos establecimientos con fines productivos e industriales, que en su aprovechamiento de las galerías abovedadas del basamento del santuario y de las conducciones subterráneas desviadas del Aniene implantaron algunas modificaciones estructurales en el santuario. En 1612 la Cámara Apostólica asentaba una fábrica de armas, y posteriormente emplazó en las ruinas un arsenal, sustituyendo al de Villa Gregoriana. Durante casi un siglo en éstas se manufacturó lana, cáñamo y lino (entre 1658 y 1740), hasta que en 1795 Pío VI inauguró la fundición que armaría a su ejército, dirigida por Carlo Lombardi y Niccola Giardoni, insertando así al monumento en el proceso de industrialización general de Roma. A consecuencia de los trabajos de 


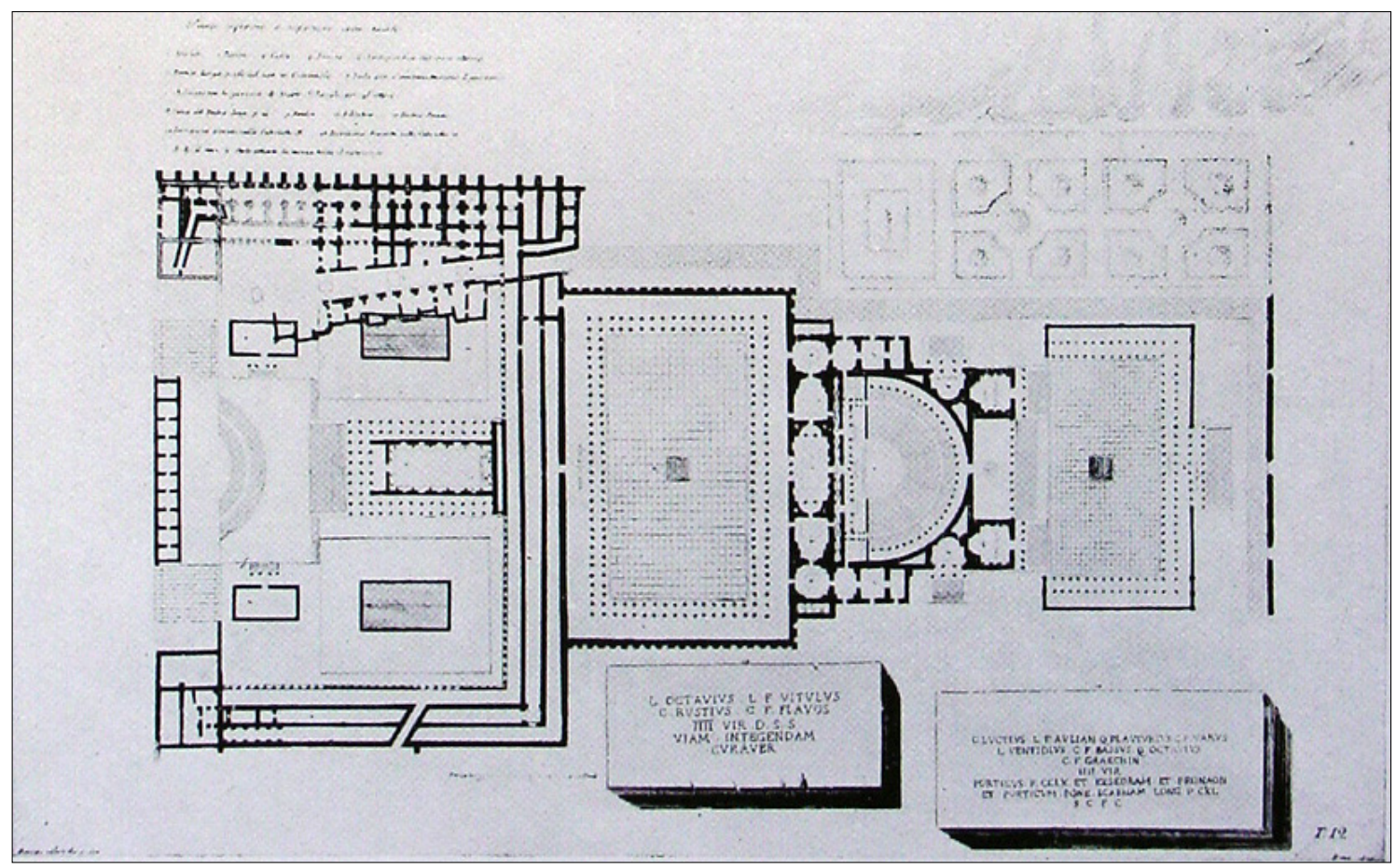

Fig. 7. L. Rossini, Reconstrucción del santuario de Hércules como el Foro tiburtino (detalle), Le antichità dei contorni di Roma, 1824-1826, lám. CII.

esos años se descombraron las galerías de los aterrazamientos inferiores, y se restauraron sus bóvedas y muros, además de añadirse algunos nuevos en las aulas del pasaje cubierto. Como dijimos, en 1793 se despejó asimismo el ángulo nororiental del área sacra, dejando al descubierto ese tramo del pórtico adornado con semicolumnas dóricas, mientras que el resto de la plataforma continuó oculta bajo las parcelas de cultivo. En 1802 el complejo pasó a manos de Luciano Bonaparte, cuya fábrica de cañones quebraba en 1815. A partir de la década de los años 30' inicia la actividad de la Ferreria de Antonio Carlandi y G. Graziosi ${ }^{35}$, que adquirida en 1846 por la Società Romana delle Miniere e sue Lavorazioni di Ferro, producirá durante cuarenta años todo tipo de instrumentos, herramientas, utensilios y maquinaria en hierro. Hacia 1885 la Società per le Forze Idrauliche adquirió la edificación y realizó el canal Canevari, tallando el eje central del santuario, incluido su templo, con el propósito de hacer funcionar la Central Hidroeléctrica de Acquoria, que servía la luz eléctrica a la ciudad. La fábrica de papel de Giuseppe Segrè, desaparecida en los años cincuenta del siglo

${ }^{35}$ Archivio di Stato di Roma (desde ahora, ASR). Camerlangato II (1824-1854). Tit. IV. Antichità e Belle Arti. Busta 276. $\mathrm{xx}$, fue el último establecimiento industrial de la pretendida Villa de Mecenas ${ }^{36}$.

Desde el Cinquecento las ruinas fueron visitadas por anticuarios y artistas, que dieron sus propias interpretaciones sobre la funcionalidad del complejo de Porta Scura. La lectura de los textos de Suetonio y de Horacio, que hablaban de la habitual presencia en Tívoli del emperador Augusto y de la demora del aristócrata C. Cilnio Mecenas determinaron que los vestigios del santuario se consideraran usualmente como una villa de éste o de aquél. En el siglo XVIII y comienzos del XIX los autores ilustrados continuaban asignando las ruinas a la Villa de Mecenas, entre ellos Volpi ${ }^{37}$, Stefano Cabral y Fausto del $\mathrm{Re}^{38}$, el abate Uggeri, Pedro José Márquez, Carlo $\mathrm{Fea}^{39}$ o

${ }^{36}$ Thomas Ashby, La campagna romana nell'età classica, Milán 1982, p. 82.

${ }^{37}$ G. R. Volpi, Vetus Latium profanum \& sacrum, Roma, 1704-1745. Volpi propuso además la conexión de la Villa de Mecenas con un templo dedicado a Hércules por medio de un pórtico. Gustavo Coccanari, Tivoli. Itinerario storico-archeologico, Tivoli 1951, p. 103.

${ }^{38}$ Stefano Cabral y Fausto del Re, Delle ville e de' piu notabili monumenti antichi della città, e del territorio di Tivoli, Roma 1779.

${ }^{39}$ Carlo Fea, Miscellanea filologica critica e antiquaria, Roma 1827, p. 26, n. 1. 
Antonio Nibby. En 1819 éste describía aún los vestigios del santuario como de una residencia de campo romana, utilizando por cierto como guía la planta delineada por los arquitectos españoles, que reproducía asimismo en su escrito ${ }^{40}$, lo cual refleja el crédito que alcanzaron los planos de Silvestre Pérez y Evaristo del Castillo y la legitimidad que les concedieron los sucesivos autores que investigaron la construcción tiburtina ${ }^{41}$. En los años siguientes tuvo la oportunidad de examinar a fondo varios de los santuarios laciales, y en 1849 señalaba la adscripción correcta de las ruinas tiburtinas, declarando la imposibilidad de que lo fueran los restos antiguos de la Catedral de San Lorenzo, considerados hasta entonces del templo ${ }^{42}$. La teoría de Nibby recibió una gran aceptación en el ámbito arqueológico del periodo, pero el santuario continuó presentando interrogantes; así, la importante publicación de Luigi Canina concerniente a la arquitectura de la Antigüedad obviaba el nombre que la tradición había otorgado al monumento e incorporaba el del santuario de Hércules, aunque estableciendo los vestigios próximos al río Aniene únicamente como un sector inferior de aquél, del cual los localizados en San Lorenzo constituirían la parte superior, casi independiente ${ }^{43}$. La planta de su templo también era deudora de la de Silvestre Pérez y Evaristo del Castillo, así como la reconstrucción de 1826 de Luigi Rossini, cuya planta contiene una conciliación de elementos extraídos de los planos de los pensionados españoles con otros directamente inventados para dar sentido a su supuesto foro tiburtino ${ }^{44}$ (Fig. 7). Por otro lado, en 1892 Lanciani aún sostenía que las ruinas de la catedral de Tívoli pertenecían al templo del héroe divinizado.

\section{II.3. La interpretación de Pedro José Márquez y LOS PENSIONADOS}

A causa de la atribución humanista del santuario a la Villa de Mecenas, tanto la restauración imagi-

\footnotetext{
40 Antonio Nibby, Viaggio antiquario ne' contorni di Roma, Roma 1819, vol. I, pp. 171-172.

${ }^{41}$ Giovanni Battista Cipriani también reproduciría la planta de los pensionados de la Villa de Mecenas, según muestra un plano publicado por Urríes de la Colina, autor que no hace constar ni la publicación en la que aparece ni su fecha. Javier Jordán de Urríes de la Colina, «El diplomático...», op. cit. n. 18 , p. 83 , fig. 6 .

${ }^{42}$ Antonio Nibby, Analisi storico-topografico-antiquaria della carta de' dintorni di Roma, Roma 1848 ( $2^{\text {a }}$ ed.), vol. III, p. 193 y ss.

${ }^{43}$ Luigi Canina, Gli edifizi di Roma antica, Roma 18481856, vol. V, pp. 120 y ss.

${ }^{44}$ Luigi Rossini, Le antichitá dei contorni di Roma ossi le più rinomate città del Lazio, Roma 1826, lámina CVII.
}

nada por los arquitectos pensionados, como el texto de Márquez, mostraban una errónea e interesada adecuación de los vestigios de Porta Scura a lo que debía de ser una casa de campo romana. Además de los dibujos, grabados al final de su opúsculo en cuatro láminas, el ex-jesuita recurría a las fuentes renacentistas que describían las antigüedades tiburtinas, renunciando a las posteriores a éstas, al considerar que simplemente habían repetido las noticias transmitidas por los anticuarios G. M. Zappi, Antonio del Re, o Pirro Ligorio. En particular de éste extraía una serie de párrafos que introducía a la par que sus explicaciones, a veces corrigiéndolas. Esto sucedía con la compleja cuestión del segundo pórtico de columnas jónicas cuya existencia rebatía Márquez, y que el anticuario napolitano aseguraba haber visto ${ }^{45}$. A partir de la descripción de Ligorio, Zappi y el resto de autores habían aceptado la veracidad de ese cuerpo superior, sin que sin embargo se verificaran trazas de él. Cabral y del Re apuntaban que albergaba estancias y lugares de habitación ${ }^{46}$, y Uggeri y Nibby confirmaban a principios del xIX su existencia, no obstante a carecer de la prueba arqueológica ${ }^{47}$. Fue el arquitecto Charles-Alphonse Thierry quien investigando en 1861 el sector noreste del orden dórico inferior halló sobre éste dos bases de pilastra y las de cuatro columnas en línea, demostrando así la veracidad del relato de Pirro Ligorio. El erudito mexicano argumentaba por el contrario que en el lado asomado al Aniene se observaban restos de un parapeto original que remataría el primer orden, lo que convertía en imposible que sobre él se elevara otro cuerpo de columnas ${ }^{48}$ (Fig. 8). En opinión de Giuliani, lo que Márquez contempló como un elemento antiguo sería producto de las restauraciones ejecutadas en 1795 en el monumento, ya que el mexicano lo había visitado una vez finalizados esos trabajos; el hecho de que los planos de Pérez y Castillo fuesen diseñados hacia 1794 podría indicar que ya en esas fechas Márquez les hubiese infundido su recelo acerca

\footnotetext{
${ }^{45}$ Acerca de las investigaciones de Ligorio en el santuario de Hércules véase Antonella Ranaldi, Pirro Ligorio $e$ l'interpretazione delle ville antiche, Studi Ligoriani 3, Roma 2001, pp. 142-153.

${ }^{46}$ S. Cabral y F. del Re, Delle ville..., op. cit. n. 38, p. 37

${ }^{47}$ Siguiendo las explicaciones de Márquez, Nibby matizaba que el cuerpo de columnas jónicas únicamente se alzaba en la parte de la edificación correspondiente a la residencia de Mecenas: «Quest'ordine superiore non esisteva tutto dintorno della villa, ma solo nel mezzo di essa dove si elevava l'abitazione particolare del padrone, le cui rovine si veggono ancora innalzarsi più di tutto il resto della fabbrica, malgrado la terra, e gli alberi, che le ricoprono». A. Nibby, Viaggio antiquario..., op. cit. n. 40, p. 172.

${ }_{48}$ P. J. Márquez, Illustrazioni della Villa..., op. cit. n. 19, p. 6.
} 


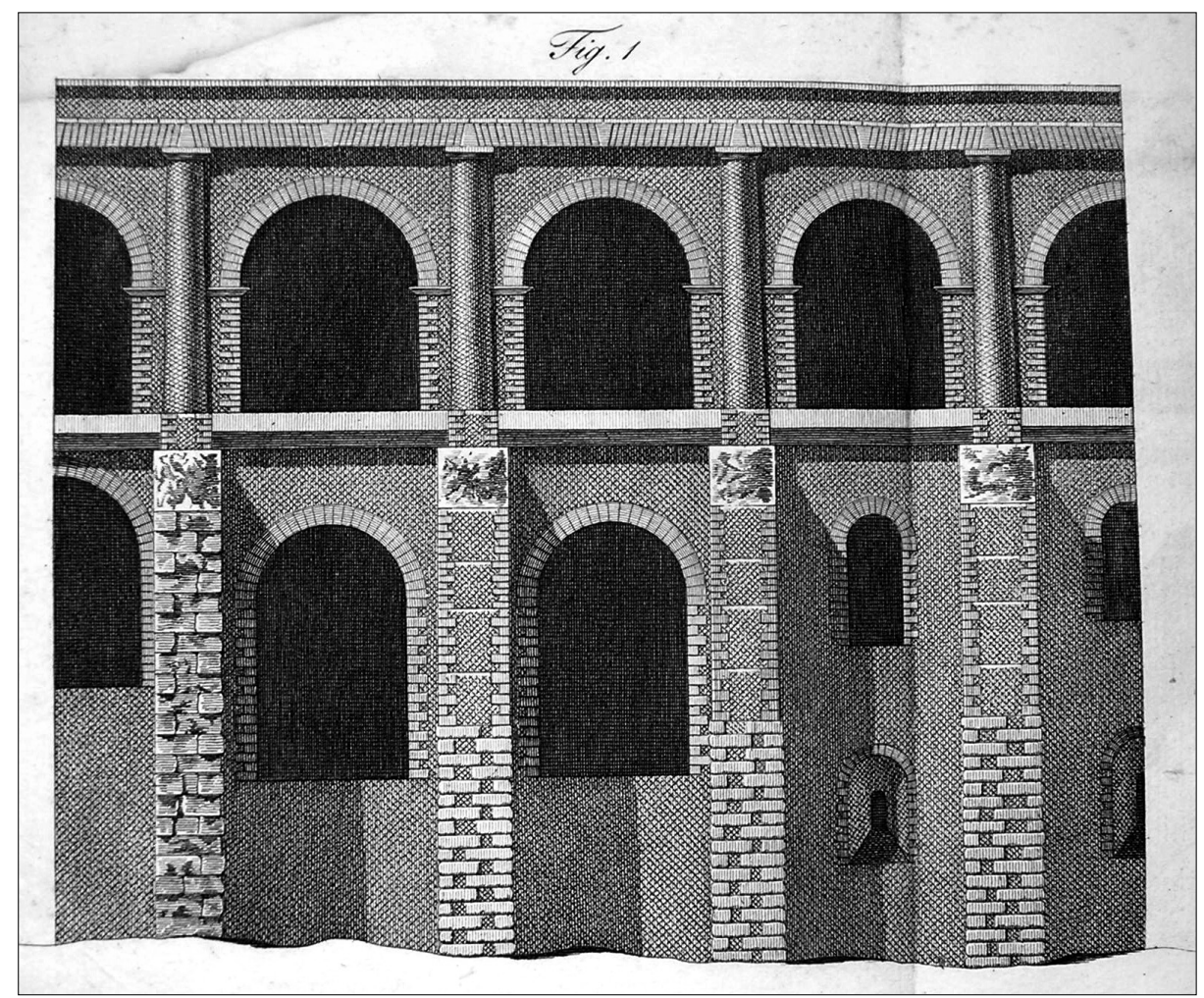

Fig. 8. P. J. Márquez, Illustrazione della Villa di Mecenate, 1812, lám. IV, fig. 1.

del orden jónico, que por supuesto no representan los pensionados en su restitución (Fig. 9). El ex-jesuita entendía que Pirro Ligorio basaba su testimonio en el hallazgo de algún indicio de este orden, proponiendo como ejemplo una columna jónica que los arquitectos de la Academia hacían figurar en el lado suroeste del área sacra $^{49}$ y de la cual Márquez determinaba que mientras que el capitel sí se habría descubierto entre las ruinas, el fuste no pertenecía a la villa y menos en aquella disposición. Esta columna era la misma que Cabral y del Re relacionaban con una de la que Zappi señalaba que estaba remataba por una estatua, y que junto a su compañera decoraría la fachada de la villa ${ }^{50}$. Los pensionados - y por consiguiente el arquitecto mexicano- solucionaron la presencia de un capitel jónico en la construcción otorgando este orden a las columnas del segundo y tercer cuerpo que delineaban en la restauración de la hipotética residencia principal de Mecenas.

La via tecta del santuario recibía la iluminación tanto de las aberturas de entrada como de cuatro lucernarios rectangulares (hoy subsisten dos, uno de

\footnotetext{
${ }^{49}$ Íd., op. cit., lám. I, letra p.

${ }^{50}$ S. Cabral y F. del Re, Delle ville..., op. cit. n. 38, p. 37.
}

ellos cegado) abiertos en la línea central de la bóveda y que daban al espacio del área sacra. En el Xvi aún no habían sido obstruidas estas cuatro aberturas por la caída de los materiales antiguos encima, pero la planta de los pensionados mostraba ya únicamente abiertos dos de ellos y una fracción del tercero, siendo restaurado sobre el plano el del sector occidental (Fig. 10). En cuanto al pasaje, el dibujo del estado de conservación de la fachada principal ${ }^{51}$ advierte claramente de la desaparición en 1793 del portón de ingreso del XVI que por ese extremo daba acceso al conjunto de establecimientos religiosos y de campos de cultivo alojados en las ruinas del monumento, y que no muchos años antes, en 1764, Piranesi había constatado en sus diseños ${ }^{52}$. La entrada actual, de finales del XIX, es obra de la Società per le Forze Idrauliche e gli Usi Industriali e Agricoli, como reza la leyenda de su arco.

En la plataforma del santuario, Silvestre Pérez y Evaristo del Castillo indicaron las medias columnas dóricas desenterradas por el Gobierno pontificio en el lado nordeste, restaurando en planta y fachada las

\footnotetext{
${ }^{51}$ P. J. Márquez, Illustrazioni della Villa..., op. cit. n. 19, lám. III, fig. 1 .
} 


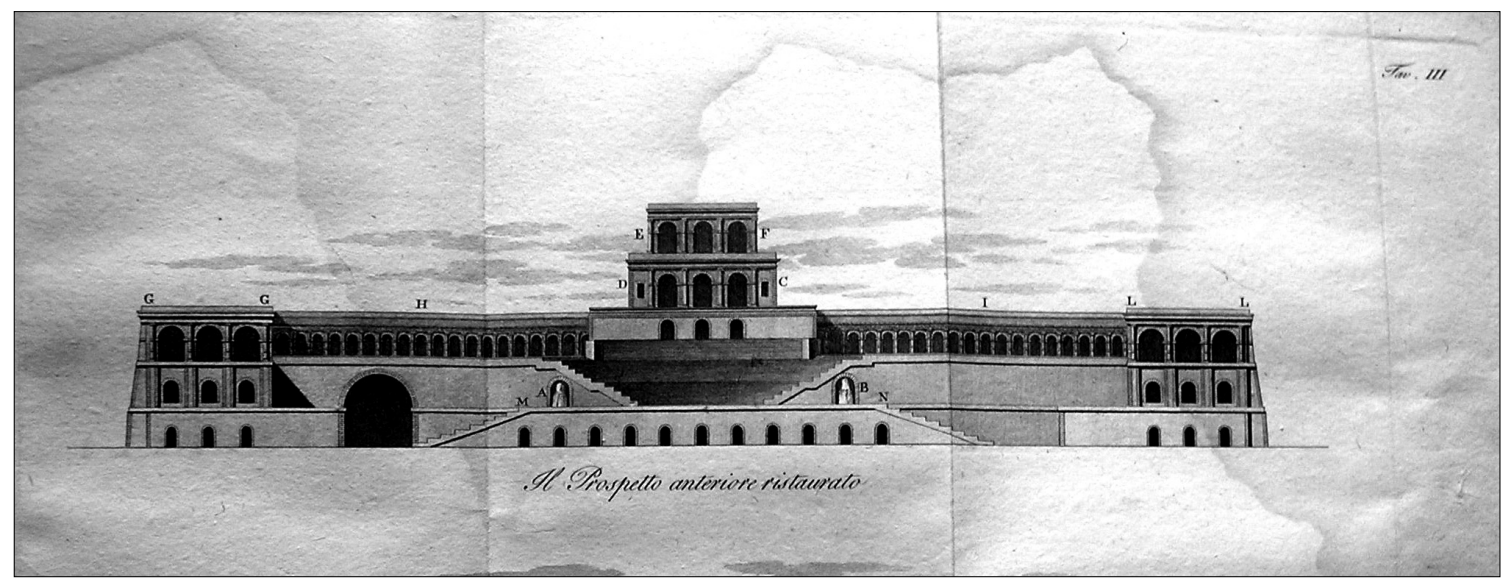

Fig. 9. P. J. Márquez, Reconstrucción de la Villa de Mecenas (detalle), Illustrazione..., 1812, lám. III.

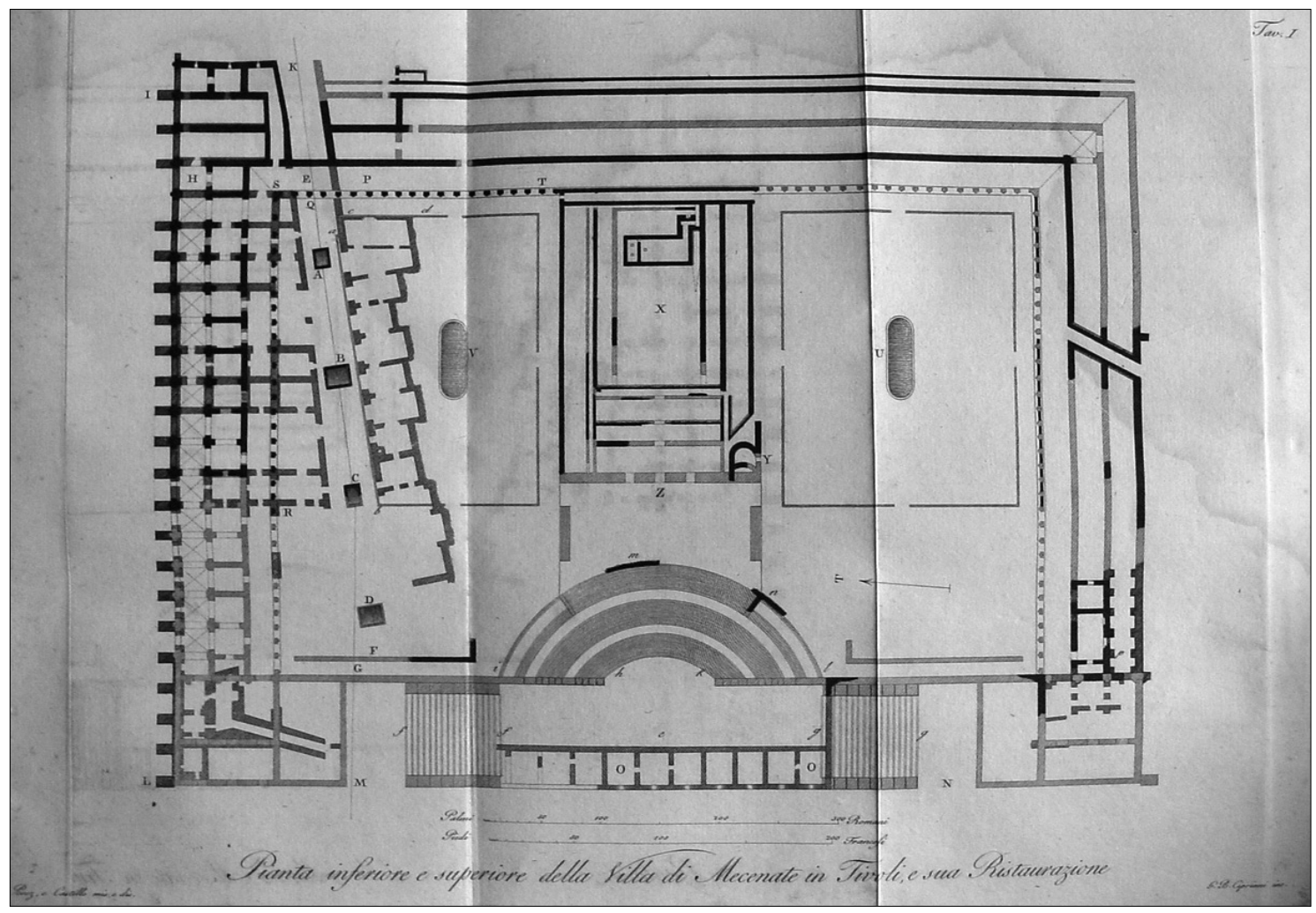

Fig. 10. P. J. Márquez, Planta de la Villa de Mecenas, Illustrazione..., 1812, lám. I.

del resto del conjunto, y situando diferentes cámaras en el amplio espacio restante entre la fachada externa y la interna de este pórtico. En el deshecho recinto que contenía la estatua del dios elevaron los tres pisos del casino del padrone, las estancias principales de Mecenas. Éstas se ordenaban en tres cuer- pos dispuestos piramidalmente, los dos últimos de los cuales repetían la combinación de arcadas y semicolumnas del pórtico anteriormente mencionado, pero con capiteles jónicos. La estructura se alzaba a modo de torre por encima del resto de la construcción, a gran altura, puesto que el anticuario G. M. Zappi 


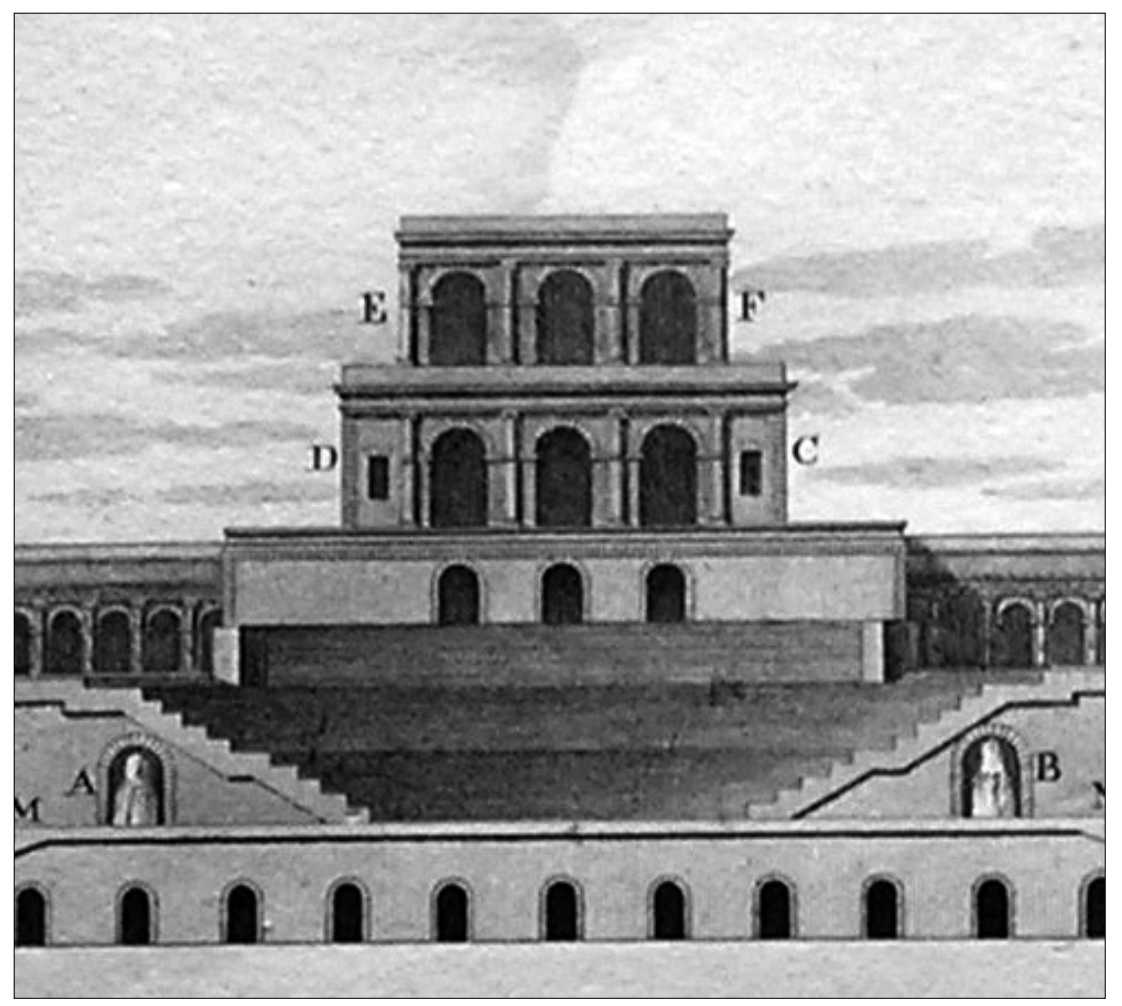

Fig. 11. P. J. Márquez, Reconstrucción de la «casa de Mecenas» (detalle), Illustrazione..., 1812, lám. III.

había escrito que de la cimentación al punto culminante del edificio la elevación era mayor que la de la basílica del Vaticano ${ }^{53}$ (Fig. 11).

Basándose en los planos y en la descripción de Pirro Ligorio el ingreso en la fachada de la edificación se reconstruía con dos escalas laterales que conducían al hemiciclo de la cávea del teatro, contemplada como otra escala más para alcanzar la plataforma principal de la villa ${ }^{54}$ (Fig. 12). Desde que aquél diseñara este graderío, ningún otro autor lo había vuelto a hacerlo constar en sus planos hasta que Silvestre Pérez y Evaristo del Castillo comprobaron la veracidad del relato de Ligorio a través de dos fragmentos curvilíneos que todavía subsistían en ese punto semienterrados entre las viñas ${ }^{55}$.

${ }^{52}$ AA. VV, Piranesi. Vedute e antichità di Tivoli, Roma 1996, p. 72, lám. 9.

${ }^{53}$ Citado en S. Cabral y F. del Re, Delle ville..., op. cit. n. 38 , p. 37.

${ }^{54}$ Los planos y dibujos de Ligorio relativos al santuario de Hércules han sido publicados en Antonella Ranaldi, Pirro Ligorio..., op. cit. n. 45, figs. 131-143.

${ }_{55}$ Estos restos se observan en la planta de los pensionados, P. J. Márquez, Illustrazioni della Villa..., op . cit. n. 19, lám. I, letras m y n, y lám. III, fig. 1 .
En las exhaustivas indagaciones efectuadas por Márquez y los arquitectos pensionados en el santuario, únicamente descubrieron restos de decoración en un friso pintado de la bóveda de una de las salas del primer pórtico, del cual se daba el dibujo ${ }^{56}$. El exjesuita aludía también al estucado que habían poseído las columnas dóricas, del que no había descubierto ningún indicio, si bien sí se han conservado algunos pocos restos casi desaparecidos. En época romana la fachada del santuario estuvo completamente enlucida y respecto a su cromatismo, se sabe solamente que la cornisa se hallaba pintada de rojo.

A comienzos de junio de 1795 José Nicolás de Azara envió a España los siete planos geométricos y las vistas del santuario ejecutadas por Silvestre Pérez y Evaristo del Castillo. La buena impresión que suscitaron facilitó la continuación del auxilio de la Academia a sus discípulos durante un año más y decidía a la institución a agradecer encarecidamente a Azara su buena dirección sobre los pensionados, cometido que Bosarte cumplía elogiando su papel desempeñado en la elaboración de los dibujos de «una

\footnotetext{
${ }^{56}$ Íd., op. cit., lám. IV, fig. 5.
} 


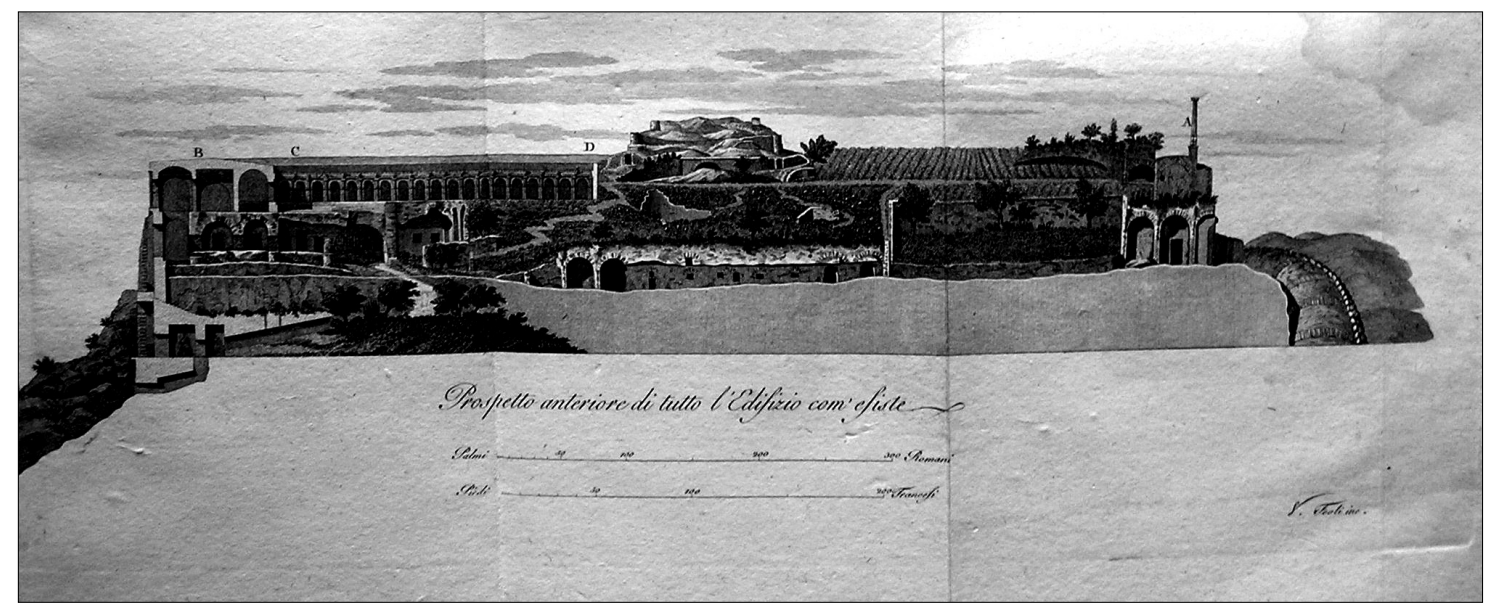

Fig. 12. P. J. Márquez, Ruinas de la Villa de Mecenas, Illustrazione..., 1812, lám. III.

obra q.e. renace á segunda vida con el calor que V.E. la ha fomentado sacandola como de un sepulcro en q.e. yacía» ${ }^{57}$. En contraste con el resto de envíos de los pensionados de esos años, de la remesa expedida a la Academia de los planos de la villa existen dos diseños en el Gabinete de dibujos de ésta ${ }^{58}$. Uno es el alzado del sector septentrional del monumento asomado sobre el río Aniene, que corresponde a la lámina II, figura 1 grabada por Cipriani, que en comparación carece de ciertos detalles que hallamos en el original. El segundo representa la parte interna del pórtico dórico en su estado de conservación y no consta en la obra de Márquez.

\section{Los Planos del Teatro de Marcelo}

Para el envío de 1796, mientras Evaristo del Castillo se proponía dibujar el Pórtico de Octavia, Silvestre Pérez delineó el único teatro que ha subsistido en Roma hasta nuestros días (aunque como observaremos, se basaría en dibujos elaborados anteriormente junto a los demás pensionados) y segundo junto al de Balbo de los edificados en el Campo Marcio en el siglo I a.C. Relata Suetonio (Caes. 44) que Julio César comenzó la construcción del teatro al sur del Circo Flaminio, pero su proyecto inconcluso lo llevó a cabo Augusto en memoria de su difunto nieto hacia el 13 a.C. Después de caer en desuso hacia mediados del siglo Iv d.C., durante la Edad Media sus ruinas se convirtieron en fortaleza de las familias que

${ }^{57}$ ASF. leg. 49-6/1. Carta de Isidoro Bosarte a José Nicolás de Azara de 16 de octubre de 1795.

${ }^{58}$ ASF. A-5427. asentaban su poder en la Urbe, sucesivamente los Pierleoni, los Fabi y los Savelli, durante cuyo dominio el teatro pasó a denominarse entre el vulgo el quliseo de' Saveli, al confundir su estructura con la de un anfiteatro ${ }^{59}$.

Con el antiguo pórtico arruinado, y el interior del teatro sepultado por los escombros y la acumulación de materiales caídos de las bóvedas, los Savelli decidieron rehabilitar el edificio en 1519, haciendo construir un palacio nuevo sobre los vestigios existentes de las arcadas de la cávea. El arquitecto sienés Baldassarre Peruzzi dirigió las obras, que salvo las lógicas transformaciones inherentes al paso de los siglos, y las restauraciones practicadas al comprar el palacio el príncipe Orsini en 1712, le dieron la fisonomía que caracterizaba al teatro en la última década del siglo XVIII ${ }^{60}$.

Si el monumento tal y como lo observamos en nuestros días es el producto de una serie de trabajos efectuados durante el periodo fascista, a finales del siglo XVIII Silvestre Pérez abordó el proyecto de un monumento todavía insertado en la confusa urbanística romana, lo que implicaba ciertas dificultades para la ejecución de los estudios de un arquitecto. Contemplando la planta de Roma de G. B. Nolli (1748), lo que llama inmediatamente la atención es esa estrecha cohesión del teatro con la inmediata arquitec-

${ }^{59}$ Ver Ch. Hüielsen, «Sulle vicende del Teatro di Marcello nel Medio Evo», Atti della Pontificia Accademia Romana di Archeologia. Rendiconti, 1923, vol. I, pp. 169-174; Bendetta Origo y Enzo Crea, Theatrum Marcelli. «El Quliseo de' Saveli», Roma 1973.

${ }^{60}$ Sobre la intervención de Baldassarre en el Teatro de Marcelo, Alberto Calza Bini, «Il Teatro di Marcello. Forma e Struttura», Separata del Bollettino del Centro di Studi per la Storia dell'Architettura, 7, 1953, pp. 7 y ss. 


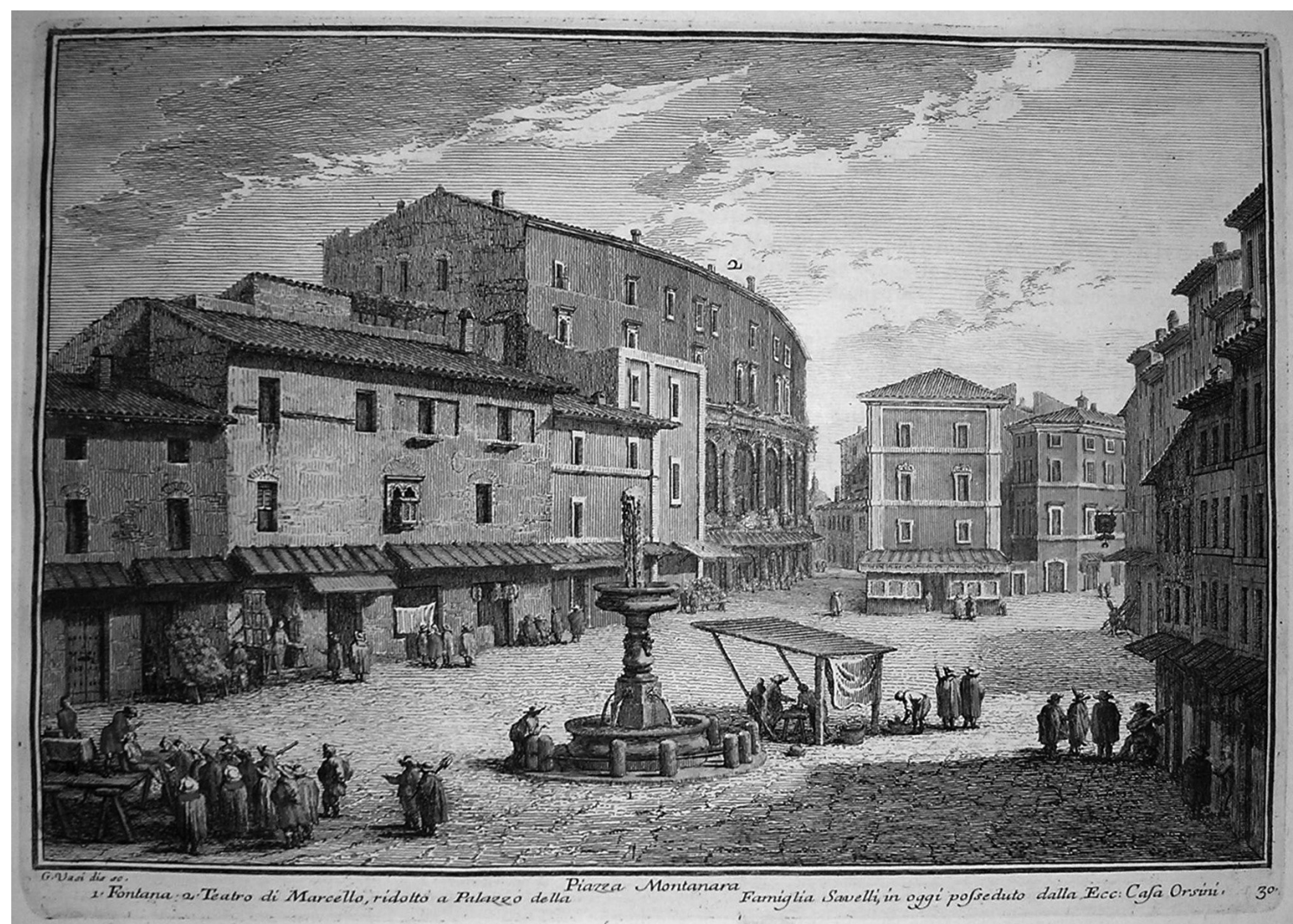

Fig. 13. G. Vasi, Piazza Montanara, Delle magnificenze di Roma..., 1752, II, lám. XXXI.

tura moderna, la angostura a la que las viviendas circundantes lo sometían hasta el punto de obstaculizar su perspectiva global, refiriéndonos siempre a su hemiciclo externo ${ }^{61}$. De norte a sur, partiendo de la Vía de Pescheria, dicha fachada se desplegaba desde la Plaza de la Catena, siguiendo por la Strada de' Sugarari (o Sugherari) hasta la Plaza Montanara, a la que asomaban ya las últimas arcadas. Así, las dos plazas constituían los dos puntos que presentaban las mejores vistas de la antigua fábrica, si bien el espacio que ofrecían continuaría manifestándose insuficiente para los propósitos de copiarlo y estudiarlo de los artistas que acudiesen allí. Los grabados y estampas del XVIII, pretendiendo resaltar el monumento, exageran la amplitud de sendas explanadas, si bien los de Vasi manifiestan mayor rigurosidad urbanística para la segunda mitad de siglo ${ }^{62}$ (Fig. 13).

\footnotetext{
${ }^{61}$ Giovan Battista Nolli, Nuova Pianta di Roma, 1748, (ed. Stefano Borsi), Roma 1994, Región XI, 976.

${ }^{62}$ G. Vasi, Delle magnificenze di Roma antica e moderna... dedicate alla sacra Real Maestà di Carlo, infantedi Spagna rè delle Due Sicile, Roma 1752, vol. II, p. XXXI.
}

En las galerías de la arcada dórica del teatro, enterradas a una profundidad de unos cuatro metros respecto al nivel original, se hacinaban bodegas de carboneros, almacenes de mercachifles, y tienduchas de baratilleros donde se comerciaba una gran diversidad de mercancías ${ }^{63}$; la zona meridional del Campo Marcio detentaba un destacado papel comercial en la ciudad por su proximidad al Tíber, por donde afluían las mercancías, y así los trabajadores del campo, los habitantes de la campiña se desplazaban hasta aquí para adquirir provisiones y aperos de labranza, y vender sus mercancías, hecho del que deriva el nombre de la Plaza Montanara, en consonancia con la infinidad de montagnuoli o montañeses que cada día confluían en aquel sitio. Sobre los vanos inferiores, las arcadas conservadas del orden jónico aparecían cegadas con muros de tufo a causa de las obras de Baldasarre, y

${ }^{63}$ A principios del siglo XIX esta serie de negocios eran propiedad de los canónicos de Santa María Maggiore, de la iglesia de Santa María del Sole, de San Angelo in Pescheria y de un privado, G. B. Brembini, que los tenían arrendadas a los comerciantes de la Vía dei Sugherari. ASR. Camerale II. Antichità e Belle Arti. Busta 9, fasc. 228. 


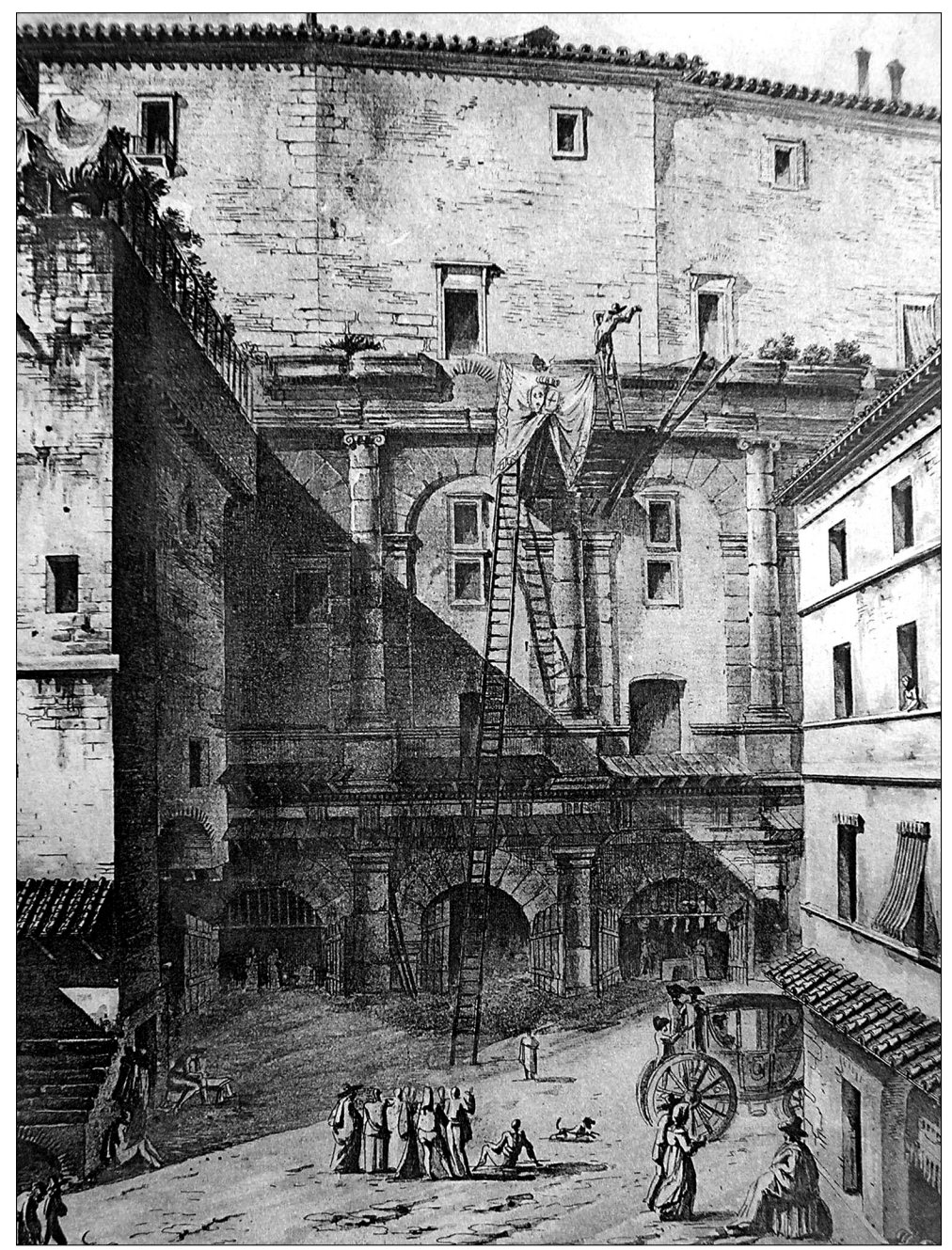

Fig. 14. H. D'Espouy y Georges Seure, Monuments Antiques relevés et restaurés par les Architectes pensionnaires de l'Académie de France à Rome, 1912, vol. II, lám. 130.

seguramente también por las intervenciones medievales que hicieron de la edificación una fortaleza. La estructura del palacio Orsini substituía la del tercer cuerpo corintio que remataba el monumento en la Antigüedad, desaparecido en su totalidad, a causa de los cual a comienzos del XIX existía la opinión de que fueran cuatro y no tres los órdenes de su fachada, cuando no que eran dos ${ }^{64}$. Algunos de los vestigios del

${ }^{64}$ M. Vasi, Itinerario istruttivo di Roma antica e moderna ovvero descrizione generale dei monumenti antichi e moderni, e delle opere più insigni di pittura, scultura, ed architettura di questa alma città e delle sue adiacenze, Roma 1819. vol. II, p. 394; Ridolfino Venuti, Accurata e succinta descrizione topografica delle antichità di Roma, Roma $1824\left(3^{\mathrm{a}}\right.$ ed.), vol. II, pp. 73 y 75 , n. 1 . interior del teatro eran accesibles a través de las bodegas del primer intercolumnio, como los pasadizos en los que se abrían las puertas de los vomitorios, o las galerías que conducían a la orquesta, gracias a lo cual los arquitectos desde el siglo xv habían sido capaces de delinear su planta, con las lógicas deficiencias suscitadas por la carencia de una completa información arqueológica.

Silvestre Pérez delineó doce planos del Teatro de Marcelo, lo que evidentemente, por las características del edificio, le llevaría algún tiempo y le obligaría a tomar medidas de todas sus partes ${ }^{65}$. Tenemos

\footnotetext{
${ }^{65}$ Indicados en un listado de la Real Academia de San Fernando de finales del siglo XVIII como: 42. Cornisa Jóni-
} 


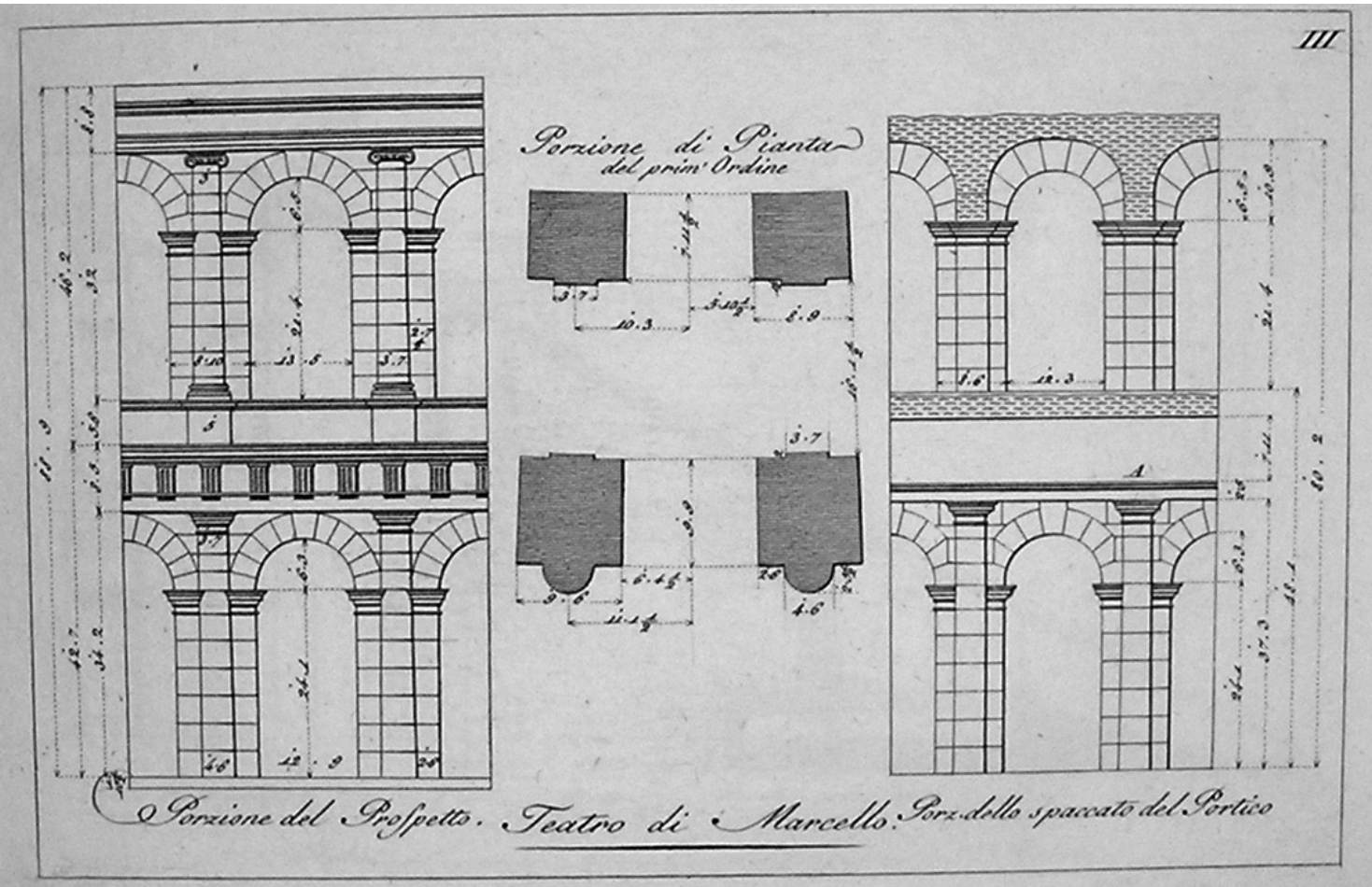

Fig. 15. G. B. Cipriani, Monumenti di fabbriche antiche, 1803, vol. III, lám. III.

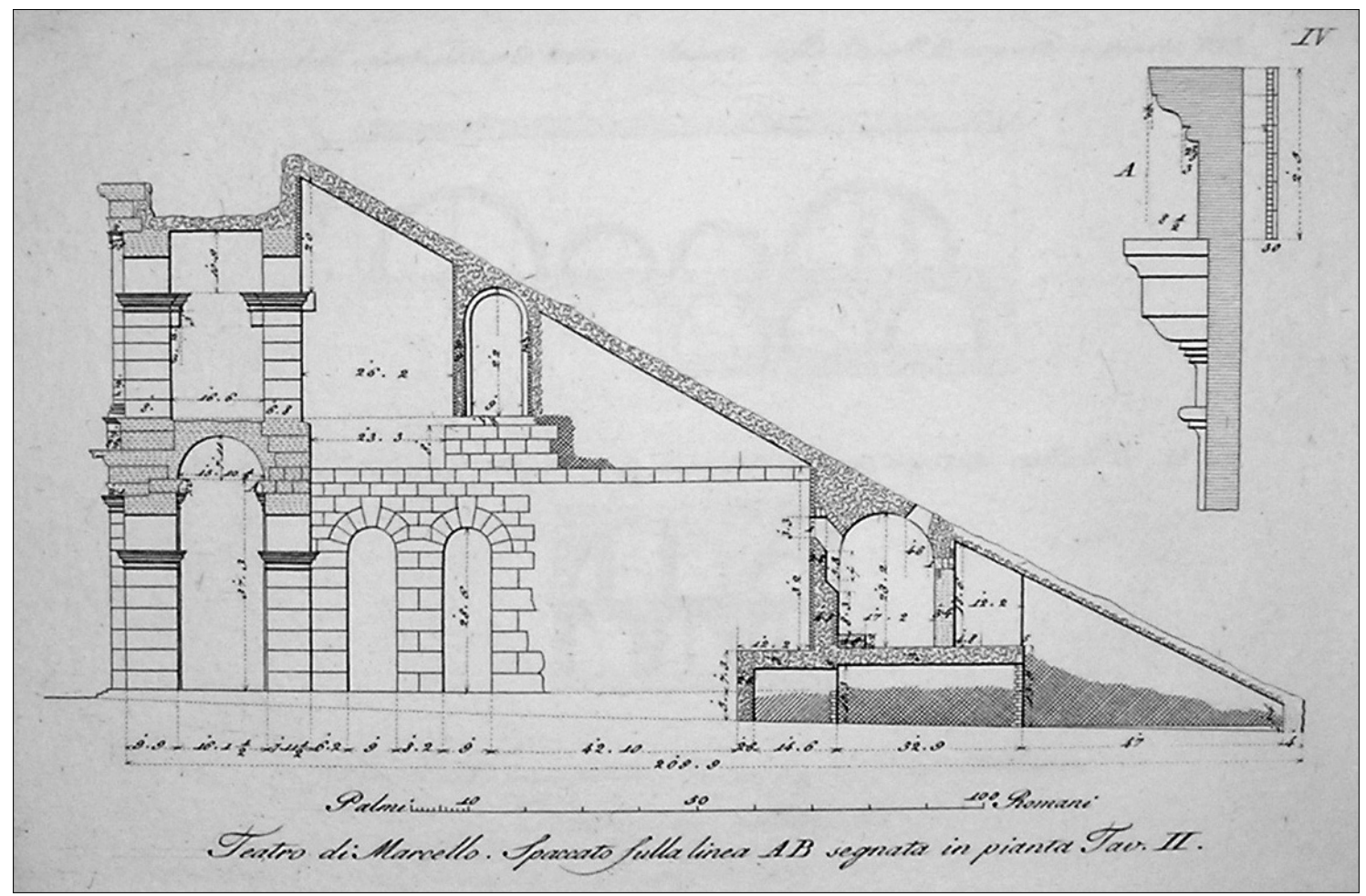

Fig. 16. G. B. Cipriani, Monumenti di fabbriche antiche, 1803, vol. III, lám. IV. 


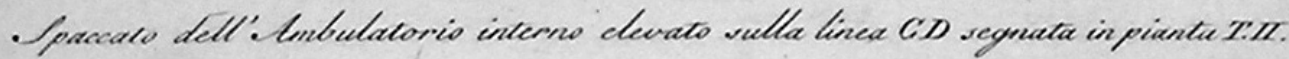
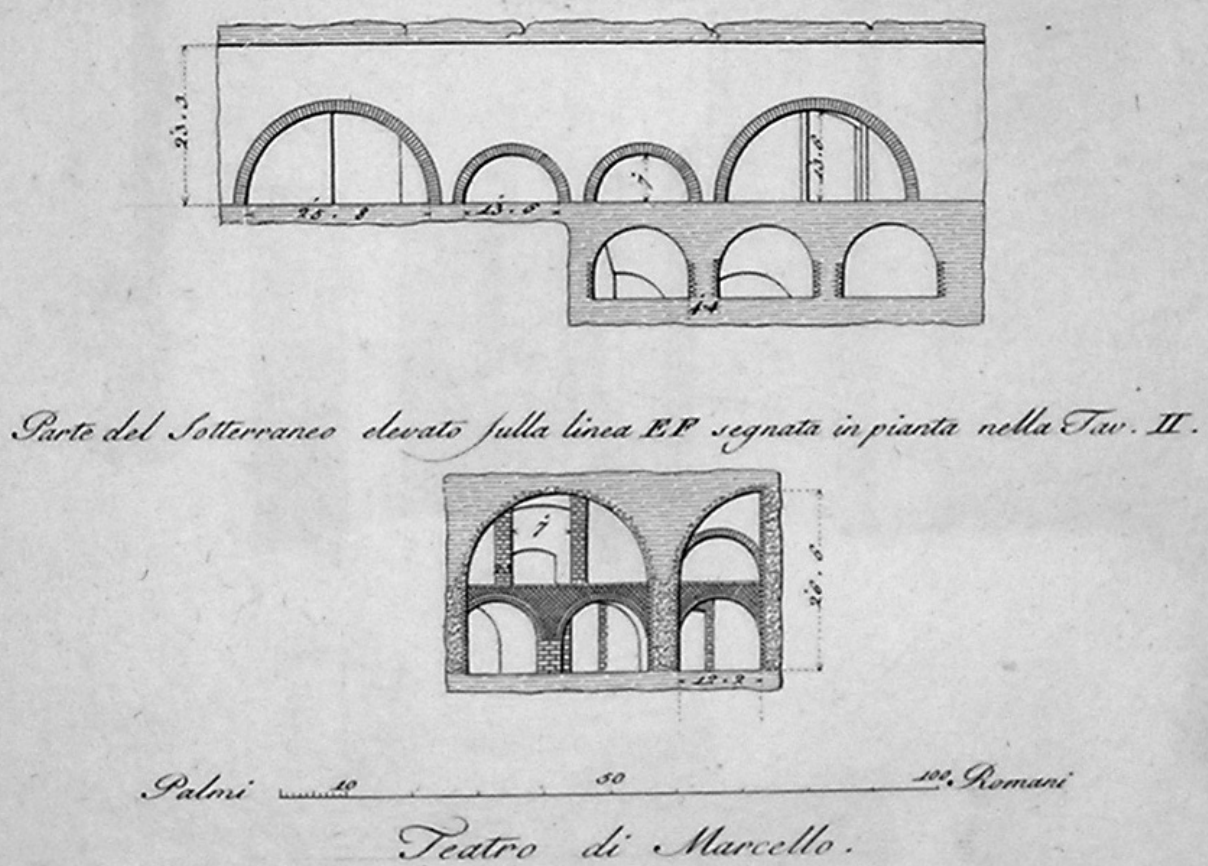

Fig. 17. G. B. Cipriani, Monumenti di fabbriche antiche, 1803, vol. III, lám. V.

constancia de que entrado el siglo XIX, los pensionados franceses que pretendían medir sus proporciones hubieron de obtener el permiso de sus aristocráticos propietarios, como es el caso de H. Labrouste en 1827 y de Th. Ballou en 1844, el último de los cuales casi tuvo que renunciar a su proyecto ante los obstáculos interpuestos por el príncipe Orsini ${ }^{66}$. A finales del XVIII la protección del patrimonio artístico no aparecía apenas regularizada y no fue hasta a partir de 1823, cuando bajo el pontificado de Pío VII se esta-

ca del Segundo orden del Teatro de Marcelo. 43. Dos Perfiles y Plantas del Cornisamento de Orden Jónico del Teatro de Marcelo con la demostracion de las pilastras de lo interior de las Galerias bajas. 44. Seccion del Portico Galeria y Tendido del Teatro de Marcelo, con parte de la planta antigua. 46. Planta Subterranea del Teatro de Marcelo. 58. Fachada del Teatro de Marcelo. 59. Capitel y basa del Orden Jonico del Seg.do. cuerpo del Teatro dho. 60. Corte del Mismo Teatro de Marcelo. 61. Costado, Perfil, y Planta del Ca pitel Jonico y dos impostas del Mismo Edificio. 62. Costado de dho. Teatro de Marcelo. 63. Capitel y Paflon de cornisam.to del Orn. Dorico de dho. Teatro. 64. Planta del Teatro de Marcelo. 65. Cornisam.to del Orn. Jonico de dho. Teatro. ASF. leg. 33-12/1.

${ }_{66}^{6}$ P. Pinon y F-X. Amprimoz, Les envois de Rome (17781968). Architecture et archéologie, Roma 1988, p. 166. bleció una normativa que controlaba la actividad de los pensionados en sus investigaciones sobre los monumentos antiguos. Un dibujo del arquitecto francés A. Vaudoyer encaramado en el teatro en el momento de medir el cornisón del orden jónico, bajo la atenta mirada de los tenderos y los usuales viandantes ociosos de la Urbe, enseña la libertad de acción con la que el mismo Pérez pudo aplicarse en el monumento ${ }^{67}$ (Fig. 14). En él se observan perfectamente muchas de las peculiaridades que hemos citado: la instalación de locales en los vanos, la casa típicamente settecentesca ocultando parte del edificio, o la escasa perspectiva ofrecida desde la plaza Montanara a causa del comienzo de la Strada de' Sugarari.

El interés de Silvestre Pérez por el monumento del Campo Marcio se remontaba al menos a 1794, cuando él, Castillo e Isidro Velázquez lo midieron y delinearon con exactitud; sus diseños, grabados en ocho láminas por G. B. Cipriani (quien añadió una más

${ }^{67}$ H. D'Espouy y Georges Seure, Monuments Antiques relevés et restaurés par les architectes pensionnaires de l'Académie de France à Rome, Paris 1910-1912, vol. II, lám. 130. 


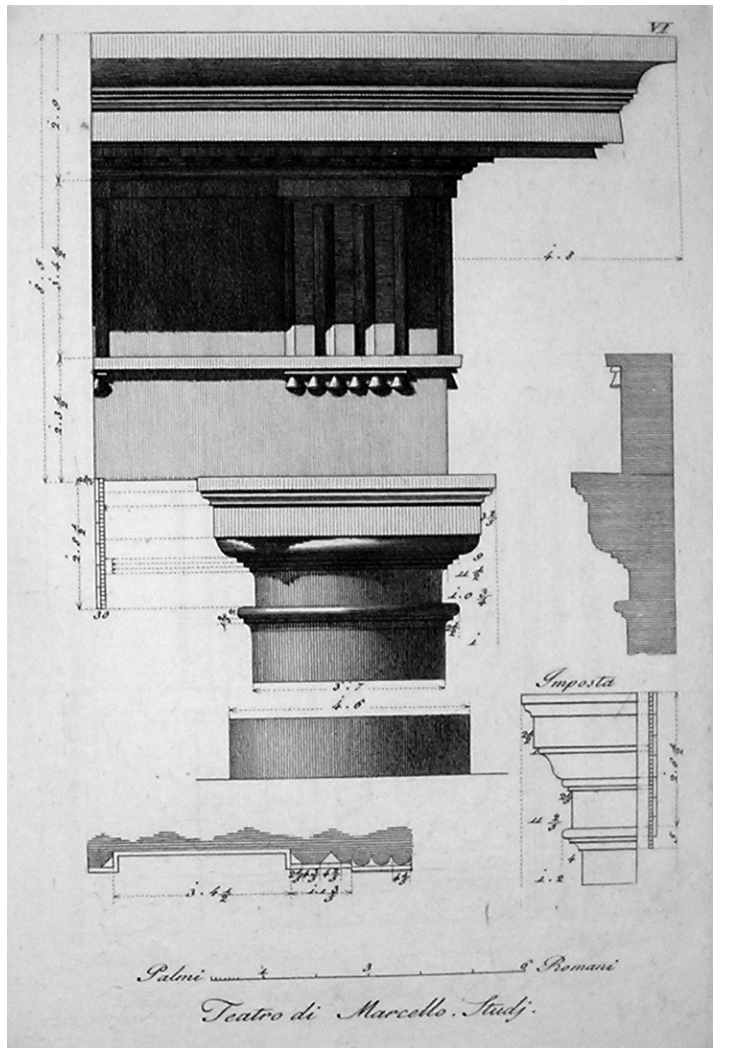

Fig. 18. G. B. Cipriani, Monumenti di fabbriche antiche, 1803, vol. III, lám. VI.

correspondiente a la planta general tomada de Desgodetz), fueron publicados en $1803^{68}$; dos años antes, el abate Uggeri había incluido en su obra Iconographie des edifices de Rome Ancienne una de las plantas del monumento reproducidas por Cipriani ${ }^{69}$. Si en esas fechas Pérez había contado con ambos compañeros como colaboradores, en 1796 Evaristo del Castillo todavía le ayudaba en su complejo pro-

${ }^{68}$ G. B. Cipriani, Monumenti di fabbriche antiche estratti dai disegni dei piu celebri autori, Roma 1803, vol. III, láms. I-IX. Las dos plantas corresponden a las láminas I y II. Precisamente una donación de Silvestre Pérez a la Real Academia de San Fernando a su muerte en 1825 fue un compendio de grabados de monumentos antiguos de Cipriani traído de Roma $-y$ por lo tanto, anterior al volumen que incluía sus propios dibujos-, y que se conservó con gran celo en la biblioteca de la institución. En 1826, cuando el Teniente Director de Arquitectura Juan Miguel de Inclán Valdés solicitó que dicha colección se pusiera a disposición de los discípulos en la Sala de Arquitectura, la Academia no le concedió su permiso al tratarse de una publicación rara, que estaría mejor custodiada en la biblioteca, donde además era muy consultada. ASF. Juntas Particulares 1814-1834, sig. 3/27. Junta particular de 20 de noviembre de 1826, p. 282.

${ }^{69}$ A. Uggeri, Iconographie des edifices de Rome Ancienne, Roma 1801, vol. II, lámina XIX.

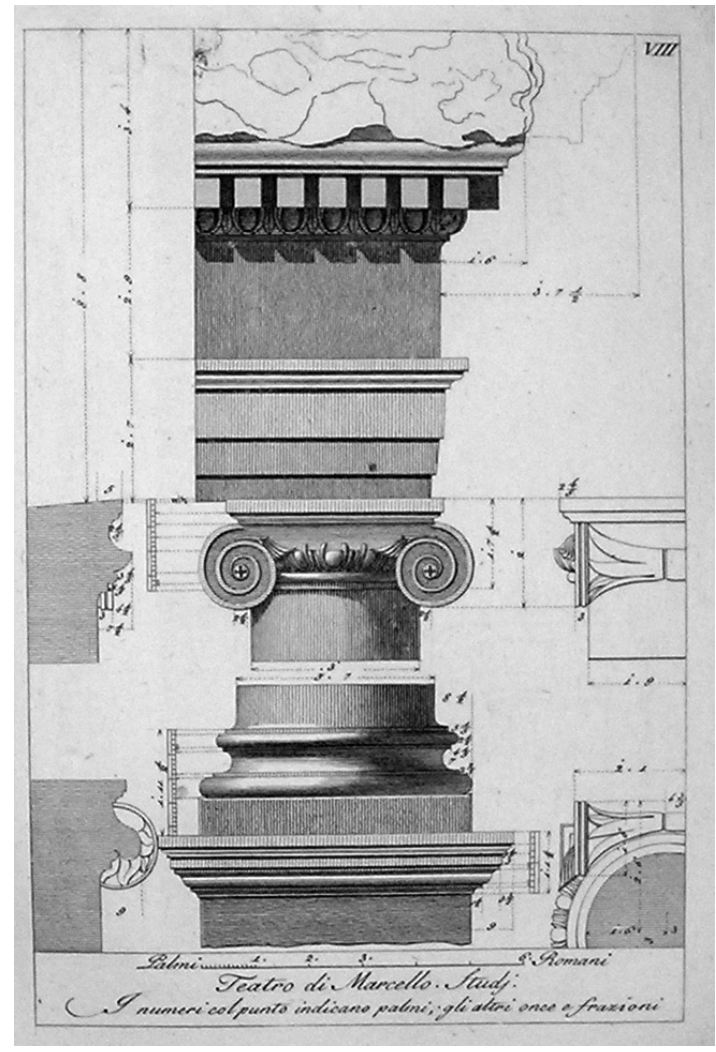

Fig. 19. G. B. Cipriani, Monumenti di fabbriche antiche, 1803, vol. III, lám. VIII.

yecto, tal vez en el proceso de precisar sus proporciones, o en sus exploraciones por los ambulacros de la cávea, si tenemos en cuenta las palabras de Azara al secretario de la Academia: «Perez y Castillo trabajan indefesam.te en el Teatro de Marcelo, y estan yà mui adelante en sus dibuxos» ${ }^{70}$.

Los planos que Pérez entregó a la Real Academia de San Fernando no se han conservado, pero la descripción de varios de ellos en los catálogos coincide con lo que plasmaban las láminas del grabador italiano, lo cual apunta que la composición de su envío no fue tanto una labor personal como una puesta en limpio de los dibujos trazados en conjunción con Castillo y Velázquez. Los diseños facilitados por Cipriani y Uggeri por tanto resultan de especial relevancia para interpretar los trabajos de 1794 y los posteriores añadidos y retoques de Pérez, así como para ayudar a desmentir la atribución a este arquitecto por parte de Carlos Sambricio - y de otros autores

${ }^{70}$ ASF. leg. 62-2/5. Isidoro Bosarte. Carta de José Nicolás de Azara a Isidoro Bosarte sin fecha, datable hacia mayo de 1796. 


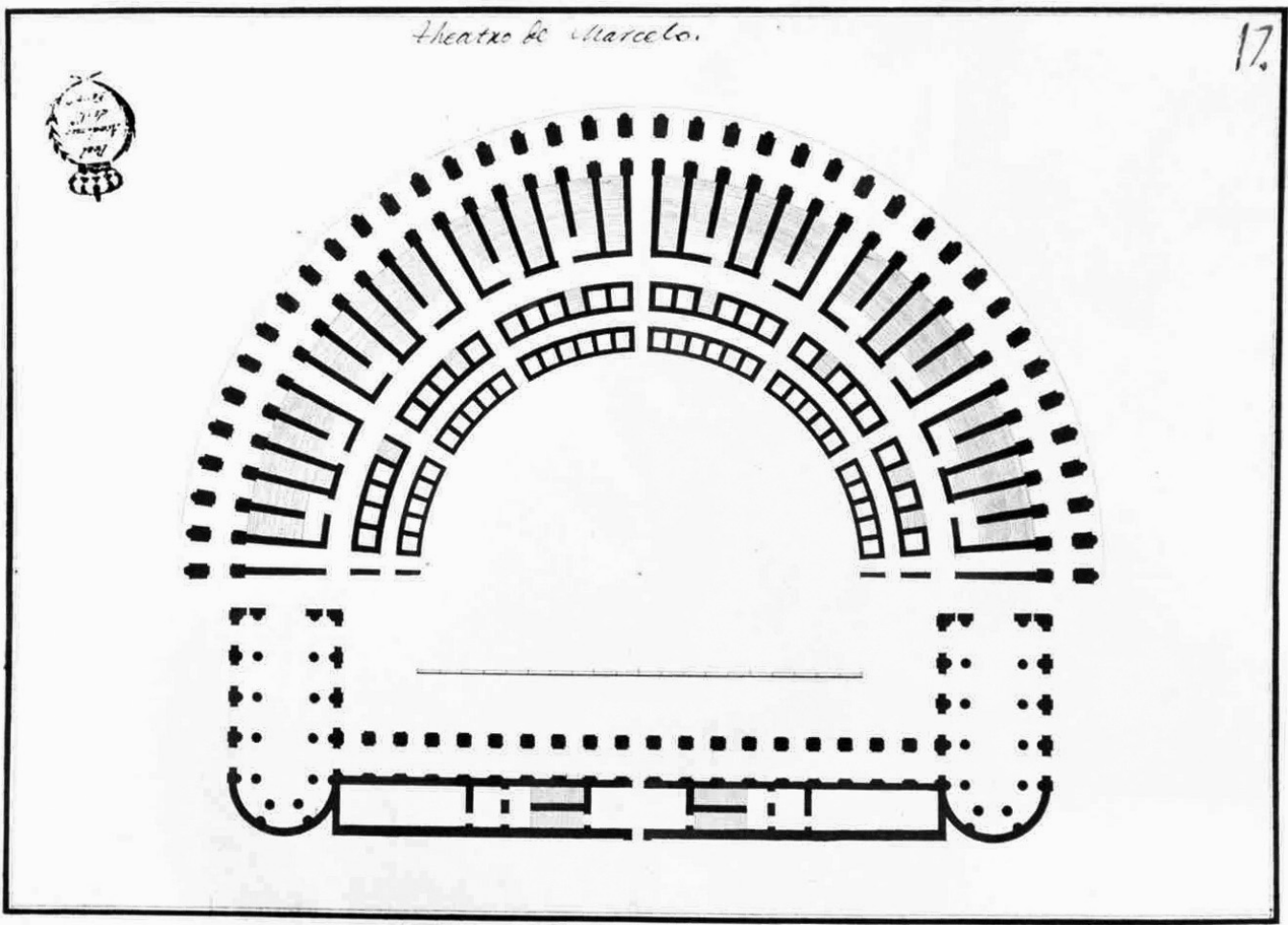

Fig. 20. Anónimo, Teatro de Marcelo (extraído de Desgodetz), ASF. A-3370.

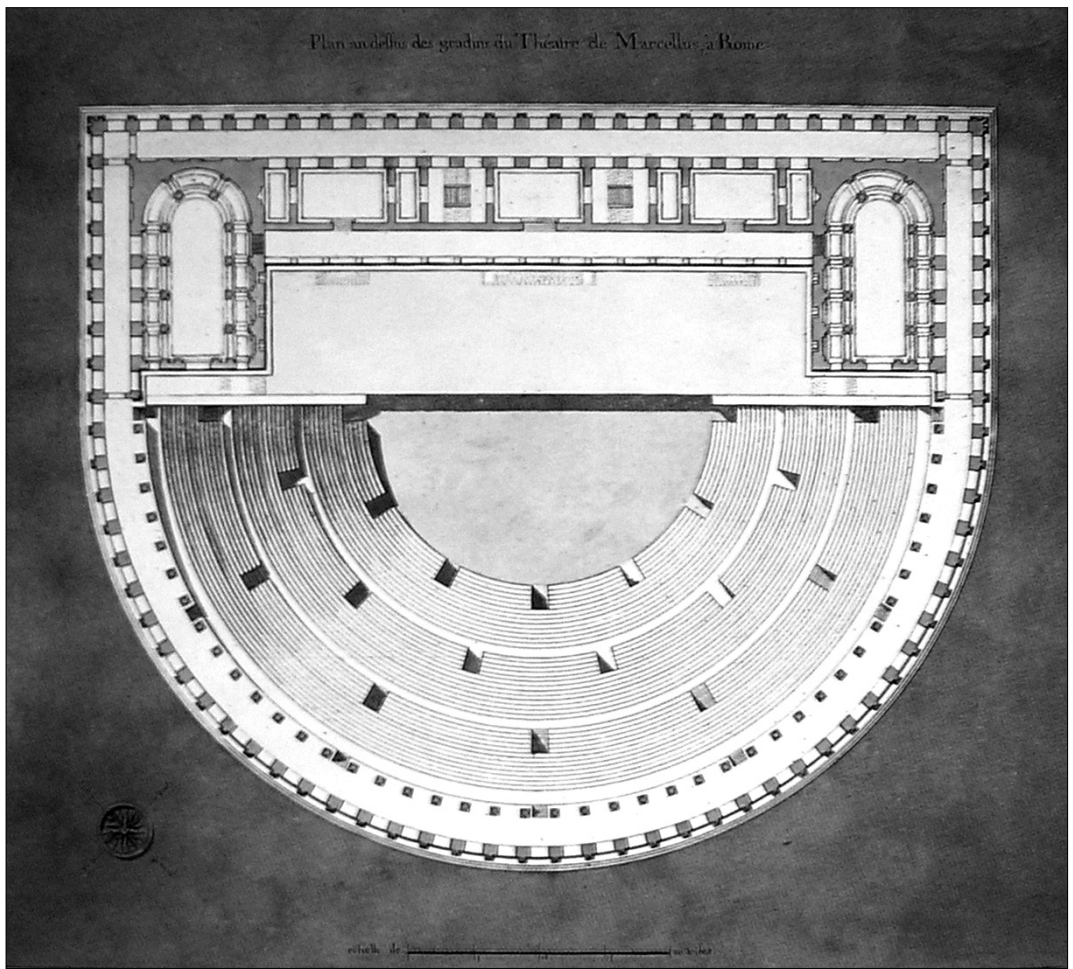

Fig. 21. A. L. T. Vaudoyer, Planta del Teatro de Marcelo, 1786 
a partir de él- de una planta del Teatro de Marcelo localizada en la Academia (ASF. A-3370), en realidad copia de Desgodetz ${ }^{71}$.

La aportación original de Silvestre Pérez residió en levantar los planos de la planta y del alzado de la fachada y los laterales del Teatro de Marcelo, además de proyectar su sección. El resto de los dibujos que ilustraron la obra de Cipriani atañían a los estudios, típicamente académicos, de los cornisamentos y los órdenes de los cuerpos de la edificación, de los capiteles y las basas de sus columnas — con sus perfiles y plantas-, las secciones de los pórticos y galerías internas, y una planta subterránea (Figs. 1519). La gran mayoría de las plantas llevadas a cabo sobre el monumento desde finales del siglo XVI seguían un modelo común, el de los planos de Baldasarre Peruzzi, que como arquitecto a cargo de las obras del Palacio Orsini, disfrutó de la ocasión de examinar las ruinas del teatro y de extraer sus conclusiones directamente de los vestigios preservados al paso del tiempo. A partir de aquí, las plantas de Serlio, de Desgodetz en el siglo XVII, o más tarde las de G. B. Guattani ${ }^{72}$ y del mismo abate Uggeri reflejaban los estudios de esa fuente original. Todavía a comienzos del siglo xx Alberto Calza Bini y Paolo Fidenzoni reconocían la importancia de Peruzzi en sus publicaciones acerca del monumento. Todos estos autores admitían su deuda con éste, y así, Desgodetz señalaba servirse en su restauración de «un plan trés ancien», mientras que Angelo Uggeri aseguraba que al hallarse una construcción moderna insertada en la edificación antigua resultaba prácticamente imposible dibujar su planta, por lo que introducía la de Serlio — además de la de Pérez, Castillo y Velázquez-, recordando que éste a su vez copiaba la de su maestro Baldasarre ${ }^{73}$. Mayor originalidad e independencia respecto a interpretaciones anteriores contenía la planta de Piranesi ${ }^{74}$, artista que aunque se empeñó en dar a conocer exhaustivamente la decoración y la arquitectura del monumento, a la hora de dibujar su planta, ésta presentaba tantas inexactitudes como las de los demás autores.

Las plantas de Serlio y Desgodetz son idénticas

\footnotetext{
${ }^{71}$ A. Desgodetz, Les édifices antiques de Rome, dessinés et mesurés très exactement, París 1682, lám. I, p. 126.

${ }^{72} \mathrm{G}$. A. Guattani, Monumenti antichi inediti ovvero notizie sulle Antichità e Belle Arti di Roma per l'anno MDCCLXXXIV, Roma 1784, vol. VI, p. 14.

${ }^{73}$ A. Uggeri, Journées pittoresques..., op. cit. n. 27, vol. I, p. 80 .

${ }^{74}$ Los numerosos dibujos de Piranesi sobre el teatro se encuentran en G. B. Piranesi, Le antichità romane, Roma 1756, vol. IV, láms. XXV-XXXVIII. Las láminas XXV y XXVI muestran la planta.
}

(Fig. 20). En ellas figuran tanto los dos cuerpos con ábside como el pórtico trasero de la escena, pero se omite la exedra que define la Forma Urbis. Basándose en las descripciones vitruvianas, Baldasarre Peruzzi -y por consiguiente los demás- situaba en este pórtico los hospitales y el aula regia mencionados por el tratadista romano distribuyéndolos en tres aulas $^{75}$. Además de en las medidas, las imprecisiones que se detectan en los planos de estos autores atañían al número de arcadas externas, situando 39 en lugar de 41, al número de accesos a la orquesta, y la multiplicación de las escalas de las galerías radiales. Tampoco tenía mucha relación con la realidad la excesiva separación entre la orquesta y la escena, así como la disposición de un tercer ambulacro concéntrico muy cercano a la orquesta además de los dos existentes realmente.

Publicada en 1812 junto al resto de dibujos de Vaudoyer $^{76}$, la planta de este arquitecto introducía un elemento extraño a las precedentes, al prolongar el ambulacro externo como si éste hubiese abrazado toda la construcción, incluidos los ambientes laterales y el pórtico, peculiaridad que ni la arqueología, ni la imagen de la Forma Urbis han constatado ${ }^{77}$ (Fig. 21). En contraposición a esta incorrección, el cálculo que aportaba del diámetro del semicírculo era prácticamente el exacto, errado sólo en diez centímetros. En esto superó a Piranesi, quien al establecer en 45 el número de arcadas incrementó en más de veinte metros el diámetro calculado para el hemiciclo del teatro.

Angelo Uggeri, que amén de clérigo era arquitecto, cayó en más equivocaciones de las provocadas por la repetición de la planta de Peruzzi, en cuanto que introdujo apreciaciones personales muy poco fundadas y rodeó las aulas que flanqueaban el pórtico con la proyección de la galería externa. El abate convirtió las salas del pórtico en espacios destinados a los actores y a los asistentes del teatro, y las laterales en pórticos cubiertos en los que el público podía distraerse en las pausas de las representaciones. A la inevitable galería en hemiciclo próxima a la orquesta le dio como objeto el tránsito de las bestias que imaginaba formasen parte de los espectáculos, dotando

\footnotetext{
75 Alberto Calza Bini, «Il Teatro...», op. cit. n. 60, p. 32.

${ }^{76}$ A. L. T. Vaudoyer, Description du Theatre de Marcellus a Rome retabili dans son etat primitif, dapres les vestiges qui en restent encore, París 1812. Sus estudios en el teatro se remitían sin embargo a 1786.

77 E. Rodríguez Almeida, Forma Urbis Marmorea. Aggiornamento generale 1980, Roma 1981, lám. XXIII. Sobre la planta de Vaudoyer, AA. VV., Roma Antiqua. Grandi Edifici Pubblici. «Envois» degli architetti francesi (1786-1901), Roma 1992, pp. 192 y ss.
} 


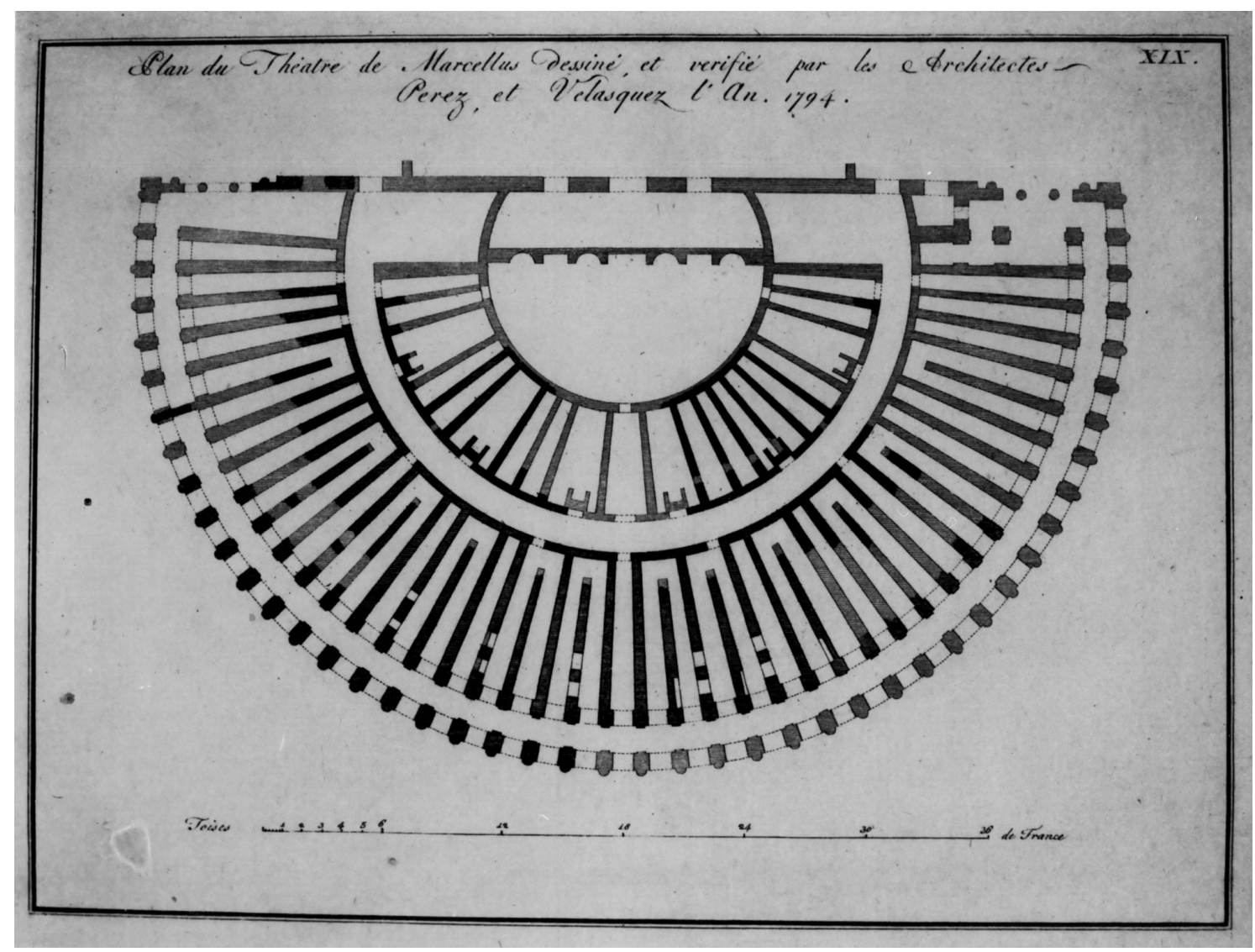

Fig. 22. A. Uggeri, Iconographie des edifices de Rome Ancienne, 1801, vol. II, lám. XIX.

a la orquesta de accesos específicos para ellas ${ }^{78}$. La planta subterránea de los pensionados españoles —en la que Uggeri, desconocedor de la participación de Castillo, hizo constar el título «Plan du Théatre de Marcellus dessiné et verifié par les Architectes Perez, et Velasquez l'An. 1794»—, muestra únicamente la cávea, la orquesta y el púlpito, por lo que el ambulacro externo se desenvuelve tan sólo a lo largo del semicírculo de la fachada (Fig. 22). La ausencia de toda la sección que se asomaba al Tíber no puede ser causada por un auténtico desconocimiento de ella por parte de sus autores, y de la que tendrían constancia a través de la Forma Urbis y de los arquitectos renacentistas y contemporáneos. Más bien parece que el interés de su diseño recae sobre la representación de los vestigios existentes del monumento, de los compartimentos y corredores radiales del interior, de algún material componente del púlpito y

${ }^{78}$ El abate señaló tanto su planta, inspirada en Serlio, como la de los arquitectos españoles, con el mismo número XIX en A. Uggeri, Iconographie..., op. cit. n.69, vol. II. las arcadas frontales, elementos que se remarcan en un tono más oscuro. La singularidad de la planta es la omisión de ese tercer ambulacro, acierto que comparten con la planta de Vaudoyer (al tratarse de una planta subterránea, no sabemos si mantuvieron los siete accesos a la orquesta tradicionales), y la coincidencia con la de Piranesi en el número de arcadas establecido, 45, cantidad que superaba la real y que incrementaría en más de veinte metros el diámetro calculado para el hemiciclo del teatro por los pensionados. Junto a los trece arcos que proseguían a la vista resaltaron la conservación de una columna más del orden dórico inferior, y que posiblemente habían examinado en el sótano de alguna de las casas adosadas al teatro.

Silvestre Pérez y Evaristo del Castillo regresaron en 1796 a España portando consigo los dibujos del teatro augusteo y del Pórtico de Octavia trazados ese año. Éstos fueron objeto de encomio por parte de los académicos de San Fernando, quienes acordaron que promocionarían a ambos pensionados ante el monarca 
para que éste les encargara en el futuro comisiones de arquitectura $^{79}$. Los planos se colgaron en la Sala de Arquitectura con sus correspondientes marcos y cristales, como se hacía habitualmente con las obras de mayor talento y que se pensaba inspirarían y fomentarían la educación artística de los discípulos de la Academia. De las copias dejadas en Italia se sirvió poco después Cipriani para componer el apartado de su repertorio de antigüedades referido al Teatro de Marcelo, gracias a lo cual hoy conocemos estos dibujos, dado que los originales no se han conservado. Junto a los planos levantados del santuario de Hércules, constituyen un conjunto de interesante docu- mentación gráfica que en España no llegó a germinar en disertaciones arqueológicas o históricas, muy al contrario que los textos y los grabados pertinentes a los monumentos antiguos de nuestro patrimonio nacional, resultantes de una gran variedad de viajes eruditos que por entonces financiaban la propia monarquía borbónica, las academias y sociedades ilustradas ${ }^{80}$.

${ }^{80}$ Sobre este tema en general véase Gloria Mora, La arqueología clásica española en el siglo XVIII: historias de mármol, Madrid 1998; Mirella Romero Recio, Historias antiguas. Libros sobre la Antigüedad en la España del siglo XVIII, Madrid 2005.

${ }^{79}$ ASF. Juntas particulares, ordinarias, generales y públicas $1795-1802$, sig. 3/86. Junta ordinaria de 4 de diciembre

Recibido el 19-06-07. de 1796 